Aus der geburtshülflich-gynäkologischen Universitäts-Poliklinik der König1. Charité.

\title{
Weiterer Beitrag zur Therapie der Geburt beim engen Becken.
}

Von

\author{
Dr. Bruno Wolff, \\ früherem Assistenten der Polikliıik.
}

In einem „Beitrag zur Lehre von der Wendung und Extraction beim engen Becken"1) habe ich über die Entbindungen der geburtshülflichen Poliklinik der Charité berichtet, in denen bei engem Becken die Wendung ausgeführt worden ist:

Ich versuchte in jener Arbeit festzustellen, eine wie grosse Bedeutung den einzelnen Bedingungen, unter denen die Wendung bezw. die Wendung und Extraction vorgenommen wurde, für den Ausgang der Geburt zukam; dabei habe ich in Betracht gezogen, wie sich die Resultate dieser Operation 1. je nach den verschiedenen Indicationen zur Wendung, 2. je nach dem Stande der Geburt zur Zeit der Wendung, 3. je nach der Anzahl vorangegangener Geburten, 4. je nach den verschiedenen Formen und Graden des engen Beckens gestalten.

Während das für jene Arbeit verwerthete Material die Entbindungen vom 1. April 1892 bis zum 1. April 1900 betraf, habe ich für die hier vorliegende Arbeit auch die Fälle mit berücksichtigt, welche vom 1. April 1900 bis zum 1. April 1902 vorgekommen sind.

Die Beobachtungen entstammen mithin einem zehnjährigen Zeitraum. -

1) Dieses Archiv. Bd. 62. 1901. 
"250 Wolff, Weiterer Beitrag zur Therapie der Geburt beim engen Becken.

Die Gesammtzahl der poliklinischen Entbindungen bei engem Becken aus diesen zehn Jahren beträgt 581 .

In 131 von diesen 581 Fällen habe ich selbst die Geburt geleitet. -

Die bei der Zusammenstellung des Materials befolgten Grundsätze sind in der oben erwähnten Arbeit erörtert. Daselbst habe ich auch auf die speciellen Vorzüge und Mängel der ausschliesslich poliklinischen Beobachtungen hingewiesen. -

Erwähnt sei hier, dass ich als "enge Becken" alle diejenigen angesehen habe, für die sich eine Conjugata vera von $9^{3 / 4} \mathrm{~cm}$ und darunter ergab. Nur solche Fälle sind berücksichtigt, in denen es sich um die Geburt reifer oder nahezu reifer (mindestens $45 \mathrm{~cm}$ langer) Kinder handelte, mit Ausschluss der macerirten Früchte und der Missgeburten. --

Was die Beckenmaasse anbetrifft, so habe ich bei der Mittheilung einzelner Entbindungen immer nur die direct gemessenen Diameter wiedergegeben. Dagegen ist bei der statistischen Zusammenstellung ganzer Reihen von Fällen, in Uebereinstimmung mit den Arbeiten von Winter ${ }^{1}$ ), Rosenthal ${ }^{2}$ ), Ludwig und Savor ${ }^{3}$ ) sowie Krönig ${ }^{4}$ ), die Conjugata vera als Maass angeführt. -

Die Conjugata vera konnte ich allerdings nicht anders als mit Hülfe des nach Michaelis-Litzmann durchschnittlich richtigen Abzuges aus der Conjugata diagonalis und externa (gewöhnlich aus der Conjugata diagonalis durch Abzug von $2 \mathrm{~cm}$ ) bestimmen.

In einer Anzahl von Fällen sind bedauerlicher Weise nur die äusseren Beckenmaasse festgestellt. Die Ermittelung der Conjugata diagonalis war nämlich unter den poliklinischen ${ }^{5}$ ) Verhält-

1) Winter, Zur Therapie des platten Beckens. Ztschr. f. Geburtshülfe und Gynäk. Bd. 13. 1886.

2) Rosenthal, Die Wendung und Extraction bei engem Becken. Arbeiten aus der Königl. Frauenklinik in Dresden. Bd. I. Leipzig 1893.

3) Ludwig und Savor, Die Geburt bei engem Becken. Wien 1897.

4) Krönig, Die Therapie beim engen Becken. Leipzig 1901.

5) Auch in Arbeiten, die sich auf ein umfassendes klinisches Material über das enge Becken stützen, musste auf die Kenntniss der Conjugata diagonalis für viele Fälle verzichtet werden. [Vergl. die Abhandlung von W. Franke aus der Königl. Fra uenklinik in Dresden (Enges Becken und spontane Geburt, in Leopold: Arbeiten aus der Königl. Frauenklinik in Dresden. Bd. II. 1895) und die ron Reifferscheid aus der Bonner 
nissen leider nicht immer möglich, weil wir häufig erst so spät zur Entbindung gerufen wurden, dass eine genaue Bestimmung der Conjugata diagonalis intra partum bereits nicht mehr vorgenommen werden konnte. Eine nachträgliche Messung derselben im wissenschaftlichen Interesse aber ist aus äusseren Gründen in der Poliklinik natürlich nicht mit Regelmässigkeit durchzuführen. -

Immerhin habe ich mich bemüht, soweit ich konnte, die Beckenmaasse möglichst genau auch durch Nachuntersuchungen nach den Entbindungen zu ermitteln, und zwar habe ich derartige Nachuntersuchungen bei 45 Frauen, die in den Jahren 1892-1902 durch die Poliklinik 94 Mal entbunden worden waren, vorgenommen. ${ }^{\text {) }}$

Von Interesse für die Beurtheilung der Beckenmessungen ist auch Folgendes: Ich fand, dass unter den 581 Geburten bei engem Becken nicht weniger als 187 Entbindungen Frauen betrafen, die in dem angegebenen Zeitraum durch die Poliklinik mehr als einmal entbunden worden sind. Die wiederholt vorgenommene Messung gewährt in diesen Fällen eine besondere Garantie für die Genanigkeit der binsichtlich des Beckens aufgenommenen Befunde. -

Bei denjenigen Frauen, bei denen wir nur die äusseren Beckenmaasse kennen, habe ich selbstverständlich nur dann ein enges Becken angenommen, wenn die verschiedenen äusseren Maasse und die gesammte Geburtsbeobachtung mit grösster Bestimmtheit das Vorhandensein eines engen Beckens mit einer Conjugata vera von $9^{3} / 4 \mathrm{~cm}$ und darunter bewiesen.

Frauenklinik (Ueber Geburten bei engem Becken. Beiträge zur Geburtshülfo und Gynäkologie. Festschrift für Professor Fritsch. Leipzig 1902)]. - „Da". sagt Franke, "ein grosser Theil der Fälle mit mässiger Beckenverengerung innerlich üherhaupt nicht, oder erst zu einer Zeit untersucht wurde, wo die innere Austastung des Beckens wegen des Kopfstandes, insbesondere die Messung der Conjugata vera nicht mehr möglich war, so musste in einer Reihe von Fällen die Entscheidung, ob das Becken verengt sei oder nicht, von den äusseren Maassen abhängig gemacht werden". - Reifferscheid weist darauf hin, dass nach Fritsch (Klinilk der geburtshülflichen Operationen) bei einer Conjugata externa unter $18 \mathrm{~cm}$ sicher ein enges Becken vorliegt. -

1) Bei denjenigen Krankengeschichten, die im Folgenden im einzelnen mitgetheilt sind, ist das Ergebniss vorgenommener Nachuntersuchung mit angegeben. Bei diesen Nachuntersuchungen habe ich auch Werth auf die Ermittelung des Zustandes der Genitalorgane nach dem Ueberstehen der Wochenbetten und auf die Feststellung des Allgemeinbefindens der Frauen gelegt. 
252 Wolff, Weiterer Beitrag zur Therapie der Geburt beim engen Becken.

Schliesslich ist hier noch zu bemerken, dass überhaupt nur Fälle berücksichtigt sind, in denen die Patientin von einem der Assistenten der Poliklinik behandelt worden ist. Die Fälle, die lediglich von den Praktikanten beobachtet wurden, habe ich fortgelassen.

Nachdem ich, wie erwähnt, die Resultate der Wendung und Extraction bei engem Becken in der vorhergegangenen Arbeit erörtert habe, will ich im Folgenden mit gütiger Erlaubniss meines hochverehrten früheren Chefs, Herrn Geh. Medicinalrath Professor Dr. Gusserow, die Ergebnisse der mit vorangehendem Kopfe veriaufenen Geburten mitheilen.

Es handelt sich hierbei um 297 Beobachtungen. -

Bei der Besprechung dieser Fälle betrachten wir:

I. Die mit vorangehendem Kopfe verlaufenen Geburten, je nachdem dieselben spontan zu Ende gingen, die Zange angelegt, oder die Kraniotomie ausgeführt w ur de.

II. Die mit vorangehendem Kopfe verlaufenen Geburten, je nach der Anzahl der vorangegangenen Geburten.

III. Die mit vorangehendem Kopfe verlaufenen Geburten, je nach verschiedenen Formen und Graden des engen Beckens. -

\section{Abschnitt I.}

Die mit vorangehendem Kopfe verlaufenen Geburten, je nachdem dieselben
A) spontan $\mathrm{zu}$ Ende gingen,
B) bei ihnen die Zange angelegt wurde,
C) die Kraniotomie ausgeführt wurde.

\section{A. Geburten, die spontan verliefen.}

Unter unseren sämmtlichen 581 Geburten bei engem Becken sind 99 (d. i. 17,0 pCt.) spontan mit vorangehendem Kopfe verlaufen. Auf die 297 insgesammt mit vorangehendem Kopfe beendeten Entbindungen berechnet, ergiebt dies $33,7 \mathrm{pCt}$. -

Die Resultate für die Kinder waren die folgenden:

Unter 100 Kindern (unter den 99 Geburten war eine Zwillingsgeburt) kamen 17 todte (bezw. in den ersten Lebenstagen gestorbene) Kinder zur Welt. Jedoch war bei 9 von den 17 todten Kindern. 
der unglückliche Ausgang durch die besondere Complication eines Nabelschnurvorfalls bedingt. Nach Abrechnung dieser 9 Fälle waren also unter 91 Kindern $83(=91,2 \mathrm{pCt}$.) lebende und 8 todtgeborene oder bald nach der Geburt gestorbene. (Mortalität $8,8 \mathrm{pCt}$.) -

Im Einzelnen ist Folgendes zn bemerken: Von diesen 100 spontan geborenen Kindern kamen zur Welt:

in 1. Schädellage: 49 ; darunter 4 todte $=8,2$ pCt.,

"2. $\quad 33 ; \quad " 3 n=9,2$ " ; ferner in (fraglich ob 1. oder 2.) Schädellage: 1 leb. Kind, in 1. Vorderhauptslage: 1 , lebend,

"1. bezw. 2. Gesichtslage: 5, darunter 1 todtes,

ferner:
$n$ 1. $n$
2. Stirnlage:
$2, \quad n$
0 todte;

in 1. Schädellage mit Nabelschnurvorfall: 5 todte Kinder,

"2.

"2. " mit Arm- u.
$3 n n$,

1 todtes Kind.

Was die Beobachtungen mit Vorfall der Nabelschnur anbetrifft, so ist einmal dem spontanen Verlauf ein vergeblicher Versuch mit der hohen Zange voraufgegangen; einmal wurde die Nabelschnur reponirt. In den übrigen 7 Fällen wurde ein Versuch zur Rettung des Kindes nicht gemacht, da das Kind, bereits ebe ein solcher stattfinden konnte, abgestorben war.

Lassen wir die durch Nabelschnurvorfall gestorbenen Kinder unberücksichtigt, so finden wir unter den spontan Geborenen:

$\left.41^{1}\right)$ Kinder von

$\mathrm{I}$-paris, mit 3 todten $=7,3 \mathrm{pCt}$.

14

6

24

im Ganzen:

$6 \quad n$

$$
\begin{array}{rllll}
\text { III- } & " & n & 1 & n \\
\text { III- } & n & n & 2 & \\
\text { IV-VII- } & n & n & 2 & n \\
\text { VIII-XIII- } & n & n & 0 & n
\end{array}
$$

50 Kinder von Mehrgebärenden, mit 5 todten $=10,0 \mathrm{pCt}$.

Dem Becken nach kamen auf:

I. Platte Becken:

Conjug. vera von $9^{3 / 4}-9 \mathrm{~cm}$ : 44 Kinder mit $3=6,8$ pCt. todten,

$\begin{array}{lllrlllll}n & n & 83 / 4 & -73 / 4 & 21 & & 2=9,5 & & \\ n & n & 71 / 2-7 & n & 6 & n & 0=0 & n & \end{array}$

1) $1 \mathrm{mal}$ Zwillinge. 
254 Wolff, Weiterer Beitrag zur Therapie der Geburt beim engen Becken.

II. Allgemein verengte Becken:

Conjug. vera von $93 / 4-9 \mathrm{~cm}: 7$ Kinder mit $0=0$ pCt. todten, " $\left.83 / 4-73 / 4 n 13^{1}\right) \quad$ " $3=23,1 n \quad n$

Die Beobachtungen, bei denen die Geburt mit lebendem reifen Kinde bei plattem Becken mit einer Conjugata vera von nur $7 \frac{1}{2}-7 \mathrm{~cm}$ spontan mit vorangehendem Kopfe vor sich ging, betrafen:

4 Erstgebärende,

1 Zweitgebärende,

1 Viertgebärende.

Besonders erwähnt seien unter diesen die folgenden:

a) Duchall (Journ.-No. 563, Jahrg. 1900/01): 23jährige Ipara. Pat. giebt an, englische Krankheit gehabt und erst zu 4 Jahren laufen gelernt Zn haben. - Rachitisch plattes Becken: Spinae 28, Cristae 29, Trochanteren $30^{1} / 2$, Conjugata externa 16, Conjug. diag. $91 / 2 \mathrm{~cm} .-2.12 \cdot 00$ : Bei unserer Ankunft ist die Blase bereits gesprungen. 1. Schädellage. Kopf mit einem kleinen Segment im Beckeneingang. Muttermund dreimarkstückgross. - Kräftige Wehen. - Circa 20 Stunden nach dem Blasensprung spontane Gelurt eines lehenden, reifen Mädchens. - Kein Dammriss. - Wochenbett normal.

Nachuntersuchung: Am 25. 10. 01: Patientin ist augenblicklich wieder gravida, und zwar im 3. Monat. Geringer Descensus vaginae. Genitalbefund im Uebrigen ohne Besonderheit. Kein Hängebauch. Das am 2. 12. 00 geborene Kind lebt und ist gesund.

b) Pretsch (Journ.-No. 471, Jahrer. 1897/98): 21 jahrige I para. Rachitisch plattes Becken: Spinae 26, Cristae 271/2, Conjug. ext. $17^{1 / 2}$, Conjug. diag. $91 / 2$. - Letzte Regel: Anfang Januar 1897. - 14. 10. 97 Mittags $1 / 21$ Uhr Blasensprung. - 1. Schädellage. - Unter kräftigen Wehen erfolgt am 16. 10. Morgens $63 / 4$ Uhr die spontane Geburt eines lebenden Mädchens. - (Das Kind ist im Jahre 1901 noch am Leben.) - (Bei der 2. Entbindung der Patientin [Polikl. Journ..No. 748, Jahrgang 1898/99] musste bei Stirnlage wegen Ausziehung des unteren Uterinsegmentes die Perforation vorgenommen werden.) -

Für die Mütter war das Resultat der spontan mit vorangehendem Kopfe verlaufenen Geburten das folgende:

Nach den 99 Entbindungen wurde im Wochenbett 8 mal. vorübergehendes Fieber ohne schwerere Complicationen beobachtet.

In einem 9. Falle, in dem die Frau schon vor der Entbindung Temperatursteigerung auf $38,5^{\circ}$ und Schüttelfrost bekommen hatte, und bei dem auch das Wochenbett fieberhaft war, ist der schliessliche Ausgang nicht bekannt; die Patientin war noch krank, als die poliklinische Behandlung abschloss. ${ }^{2}$ ) -

1) $1 \mathrm{mal} \mathrm{Zwillinge.}$

2) Fall Hähnel: Journ. No. 245. Jahrg. 1893/94. 
Zweimal trat Exitus letalis ein.

Unter diesen beiden Fällen ist in einem, in dem die Patientin 6 Stunden post partum starb, die Todesursache (Lungenembolie?) nicht mit Sicherheit ermittelt worden:

Fall Kroll (Journ.-No. 323, Jahrg. 1895/96): Allgemein verengtes und rachitischos Becken: Spinae 23, Cristae 25, Conjug. ext. $16 \frac{1}{2}$ bis $17 \mathrm{~cm}$ - 34 jährige II para. Die Pat. hatte, schon ehe ärztliche Hülfe eintraf, Schüttelfrost und Temperatur $38,9^{\circ}$, Puls 105 bekommen. -Circa 3 Tage nach dem Blasensprung erfolgte spontan in 2. Schädellage die Geburt eines todten, reifen Knaben. - 6 Stunden post partum trat plötzlich der Tod der Mutter ein. Die Section ergab: Uterus ganz intact, gut contrahirt; keine Blutung. In der Bauchhöhle freier Ascites. - Die weitere Section war nicht gestattet.

Die andere Patientin $\left.{ }^{1}\right)$ starb an Sepsis. Sie fieberte ebenfalls schon vor der Geburt des Kindes. Nach der Geburt. desselben trat eine sehr starke Blutung ein, die zu hochgradigster Anämie führto und die manuelle Placentarlösung nothwendig machte.

Schliesslich ist noch zu erwähnen, dass schwerwiegende Verletzungen der Mutter (Dammrisse 3. Grades, erhebliche Cervixrisse etc.) nicht vorkamen. -

Ueberblicken wir diesen Berjcht über die mit vorangehendem Kopfe spontan verlaufenen Entbindungen, so muss auf den ersten Blick auffallen, wie gering (nur 17,0 pCt. unter unseren sämmtlichen 581 Geburten bei engem Becken) die Anzahl der spontan beendeten Fälle ist.

Diese Thatsache ist aber nicht etwa in einem besonders activen Vorgehen begründet. Im Gegentheil wurden, den Vorschriften Herrn Geheimrath Gusserow's entsprechend, operative Eingriffe nicht anders als auf stricte Indication von Seiten der Mutter oder des Kindes hin vorgenommen (abgesehen natürlich von den Fällen, bei welchen des engen Beckens wegen prophylaktisch gewendet wurde).

Es liegt vielmehr im Charakter der Poliklinik, dass der Procentsatz der spontan verlaufenen Geburten immer nur ein verhältnissmässig geringer sein kann; denn bei Weitem in den meisten Fällen werden wir zur Entbindung garnicht des engen Beckens wegen gerufen, sondern nur deshalb, weil sich in Folge des engen Beckens oder aus einem anderen Grunde besondere Störungen im Geburts-

1) Fall Kr üger: Polikl. Journal No. 686. Jahrgang 1901/2. 
256 Wolff, Weiterer Beitrag zur Therapie der Geburt beim engen Becken.

verlaufe zeigen, die dann gewöhnlich mehr oder weniger bald die künstliche Beendigung der Geburt indiciren. -

Was das unter den poliklinischen Verhältnissen bei den spontan verlaufenen Entbindungen erzielte Resultat anbetrifft, so war dasselbe etwas ungünstiger als beispielsweise das in der Dresdener Frauenklinik erreichte, über das Franke ${ }^{1}$ ) berichtet hat. Unter den spontan geborenen Kindern bei engem Becken waren dort nur 1,6 pCt., deren Tod durch das enge Becken verschuldet war, während wir eine Mortalität von $8,8 \mathrm{pCt}$. aufzuweisen hatten. - -

Die Becken mit einer Conjugata vera von $83 / 4-73 / 4 \mathrm{~cm}$ zeigten sowohl bei den platten wie bei den allgemein verengten Becken eine höhere Mortalität als die mit einer Conjugata vera von $93 / 4$ bis $8 \mathrm{~cm}$.

Auffallend giinstig war dagegen das Ergebniss in den 6 Geburten bei platten Becken mit einer Conjugata vera von nur $71 / 2-7 \mathrm{~cm}$. Hier kamen stets lebende Kinder zur Welt. -

Die beiden Todesfälle, die sich bei den Müttern ereigneten, sind in einen directen Zusammenhang mit dem engen Becken nicht zu bringen. -

\section{B. Die Zange bei engem Becken.}

Es sind von unserem Material hier zu erörtern:

a) 147 Fälle, in denen die Geburt durch die Zange beendet wurde, und ausserdem

B) 14 Fälle, in denen ein vergeblicher Versuch zur Beendigung der Geburt mit der Zange gemacht wurde.

Von diesen letzteren 14 Fällen verlief einer nach dem vergeblichen Zangenversuch spontan; in den übrigen 13 Beobachtungen wurde im Anschluss an diesen Eingriff die Kraniotomio ausgeführt. -

Im Folgenden unterscheiden wir:

a) gewöhnliche Zangen (bei im Becken stehendem Kople): 90 Fälle;

b) hohe Zangen: 71 Fälle (einschliesslich 14 vergeblicher Versuche mit der hohen Zange). -

Bei dieser Eintheilung habe ich, nach der an unserer

1) Franke, Enges Becken und spontane Geburt. In Leopold, Arbeiten aus der Kgl. Frauenklinik in Dresden. Bd. II. 1895. 
Klinik üblichen Bezejchnung, alle diejenigen Operationen zu den hohen Zangen gezählt, bei welchen bei der Anlegung des Forceps das Promontorium noch mit geradem oder noch leicht mit gekrümmtem Finger zu erreichen war, der Kopf also nur mit einem kleinen Segment oder auch schon mit seinem grössten Durchmesser im Beckeneingang stand.

a) Gewöhnliche Zangen:

Hierher gehören:

๙) 22 typisehe Beckenausgangszangen,

ß) 22 Zangen bei tiefem Querstand,

r) 42 Zangen bei in der Beckenweite oder Beckenenge stehendem Kopfe,

d) 4 Zangen bei im Becken stehendem Kopfe, bei denen die genauere Angabe über den Stand desselben fehlt. -

Die Resultate bei diesen Zangenoperationen waren für die Kinder die folgenden:

Von den 90 Kindern kamen 6 todt zur Welt oder starben innerhalb der ersten Tage nach der Geburt. 84 blieben am Leben.

Von den 6 todten oder bald nach der Geburt gestorbenen Kindern war bei einem der Tod durch Nabelschnurvorfall bedingt. Nach Abrechnung dieser Geburt kamen also auf 89 Kinder 84 lebende und 5 todte oder bald nach der Geburt gestorbene (Mortalität: $5,6 \mathrm{pCt}$.).

Mittelst der bei im Becken stehendem Kopfe angelegten Zange wurden geboren:

in 1. Schädellage: 49 Kinder mit 2 todten $=4,1 \mathrm{pCt}$,

in 2. $\quad 32 \quad n \quad n 2 n=6,25 n$;

ausserdem in (fraglich ob 1. oder 2.) Schädcllage: ein lebendes Kind,

in Vorderhauptslage (3. bezw. 4. Schädellage): 6 Kinder mit 0 todten,

in 2. Gesichtslage: ein todtes Kind; ferner in

1. Schädellage mit Nabelschnurvorfall: ein todtes Kind.

In der dureh Nabelschnurvorfall complicirten Beobachtung war die Nabelschnur bereits pulslos, ebe die Zange angelegt wurde. (Fall Schmidt, Journ.-No. 128, Jahrg. 1898/99.) 
258 Wolff, Weiterer Beitrag zur Therapie der Geburt beim engen Becken.

Lassen wir das durch den Vorfall der Nabelschnur gestorbene Kind unberücksichtigt, so kamen auf:

67 Kinder von Iparis: 4 todte $(2$ todtgeborene, 2 bald nach der Geburt gestorbene) $=6,0 \mathrm{pCt}$,

10 Kinder von Ilparis: 0 todte

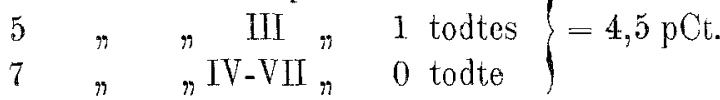

Dem Becken nach kamen auf:

Platte Becken:

Conjugata vera von $93 / 4-9 \mathrm{~cm}: 43$ Kinder mit 2 todten $=4,7 \mathrm{pCt}$. n $\quad$ n $83 / 4-73 / 4 \mathrm{~cm}: 13 n \quad, 1 \quad n=7,7 \mathrm{pCt}$.

Allgemein verengte Becken:

Conjugata vera von $9^{3} / 4-9 \mathrm{~cm}: 16 \mathrm{Kinder}$ mit 0 todten $=0$ pCt. $n \quad n \quad 83 / 4-73 / 4 \mathrm{~cm}: 16$ Kinder mit $2,=12,5 \mathrm{pCt}$. $" \quad n 7 \frac{7}{2}-7 \mathrm{~cm}$ : ein lebendes Kind.

In diesem letzteren Falle, in dem bei einem allgemein verengten Becken mit einer Conjugata vera von nur $7 \frac{1}{2} \mathrm{~cm}$ die Zange an den in der Beckenweite stehenden Kopl angelegt wurde, handelte es sich um eine künstliche Frühgeburt: ${ }^{1}$ )

Fall Vogt (Journ.-No. 780, Jahrg. 1895/96): Allgemein verengtes Becken: Spinae 24, Cristae 27, Conjug. ext. 17, Conjug. diag. $91 / 2 \mathrm{~cm}$.

1. Geburt: Perforation. 2. Geburt: Verschleppte Querlage, Wendung, todtes Kind.

28. 1. 96 Vormittags: 30 jährige Illgravida mensis IX. -- Finleitung der künstlichen Frühgeburt mittelst Dilatatoren. - 31.1. 1/28 Uhr Norgens: Blasensprung bei einmarkstückgrossem Muttermund, Kopf beweglich über dem Beckeneingang. - Wehenstillstand. - 1. 2. Morgens 11 Uhr: kräftige Weben. 9 Uhr Nachmittags: Muttermund bandtellergross. Kopf ist mit gesenkter kleiner Fontanelle fest in das Becken eingetreten. - 2. 2. Morgens 1 Uhr: Kopf in der Beckenweite. Muttermund vollständig erweitert. Kindliche Herztöne beschleunigt. - Zange. Tief asphyktischer, nacb $3 / 4$ Stunden wiederbelebter, $48^{1 / 2} \mathrm{~cm}$ langer, $2400 \mathrm{~g}$ schwerer Knabe. Wochenbett normal. Hutter und Kind werden 14 Tage später gesund aus der Beobachtung entlassen.

Was die Resultate dieser Zangenoperationen für die Mütter anbetrifft, so wurde in 15 Fälen im Wochenbett Fieber

1) Es ist dies die einzige künstlicbe Frühgeburt bei unserem hier verwertheten Material, da diese Operation sonst nicht poliklinisch, sondern immer nur nach Aufnahme der Patientin in die Klinik ausgeführt worden ist. 
beobachtet; einmal bildete sich eine Venenthrombose, einmal eine Parametritis aus.

Todesfälle der Mütter kamen nicht vor.

An Verletzungen wurden vermerkt:

Dammrisse 1.-2. Grades (bezw. Dammincision): 24 , 3. $"$. . . . . . . 2 , Incisionen in den Muttermund: . . . . . . 1.

In den beiden Fällen, in denen ein Dammriss 3. Grades zu Stande kam, handelte es sich um ältere Erstgebärende: (1) Fall Jäkel. Journ.-No. 243, Jahrg. 1898/99: 27 jährige I-para. Allgemein verengtes Becken. - 2) Fall Schulz. Journ.'No. 763, Jahrg. 1899/00: 32jährige I-para. Einfach plattes Becken.] Die erstgenannte Beobachtung betraf eine Zange bei tiefem Querstand, die zweitgenannte eine typische Beckenausgangszange, die durch Temperatursteigerung bei der Mutter und erböhte Frequenz der kindlichen Herztöne indicirt war.

\section{b) Hohe Zangen (einschliesslich der vergeblichen Versuche mit der hohen Zange).}

Von den 14 Fällen, in denen nur ein vergeblicher Versuch mit der hohen Zange gemacht wurde, ist der eine auch bereits bei den spontanen Geburten mitgezählt; die 13 anderen, bei denen nach dem Zangenversuch perforirt wurde, werden bei. der Besprechung der mittelst Kraniotomie beendeten Geburten ebenfalls Berücksichtigung finden.

Es ist aber trotzdem nothwendig, diese Beobachtungen auch hier bei den hohen Zangen-Operationen mit in Betracht zu ziehen. $\mathrm{Nagel}{ }^{1}$ ) hat mit Recht betont, dass man sich ein richtiges Bild von der hohen Zange nur dann versehaffen kann, wenn "diejenigen Kraniotomien, denen Zangenversuche vorausgegangen waren, mit in die Liste aufgenommen werden. Dadurch wird der Erfolg der Zange ein erheblich ungünstigerer, aber zugleich den wirklichen Verhältnissen mehr entsprechend".

Ein vergeblicher Zangenversuch zieht ja doch oft genug die Nothwendigkeit der Perforation nach sich. -

Was die Ausführung der hohen Zangen-Operationen anbetrifft, so kam in einer Reihe von Fällen die gewöhnliche Nägelesche Zange zur Verwendung; in einer anderen Reihe von Beobachtungen wurde die Achsenzugzange benutat.

1) Nagel, Erfahrungen über die Anwendung der Achsenzugzange. Dieses Archiv. Bd, 39. 1891. 
Meinen eigenen Erfahrungen mit letzterem Instrument zufolge kann ich mich der warmen Fürsprache, die dasselbe besonders in den Arbeiten Nagel's') gefunden hat, durchaus anschliessen. -

Die Indication zur Anlegung der hohen Zange gaben ab:

a) Störungen, die lediglich im Befinden des Kindes constatirt wurden: in 11 Fällen.

b) Störungen, die lediglich im Befinden der Mutter constatirt wurden: in 21 Fällen.

c) Störungen, die sowohl im Befinden der Mutter wie in dem des Kindes constatirt wurden: in 39 Fällen. -

Die Resultate für die Kinder waren die folgenden:

Von den 71 Kindern, bei denen die Geburt mit der hohen Zange vollendet oder dieselbe wenigstens versuchsweise angelegt wurde, blieben 49 am Leben; 22 kamen todt zur Welt oder starben in den ersten Tagen. Von den 21 todten Kindern war bei einem der Tod durch Nabelschnurvorfall bedingt, ein anderes war mit Sicherbeit schon vor Anlegung der Zange todt2).

Nach Abrechnung dieser letzteren beiden Geburten kamen also auf 69 Kinder: 49 lobende und 20 todte oder bald nach der Geburt gestorbene (Mortalität 29,0 pCt.).

(Würden wir die vergeblichen Zangenversuche nicht mitrochnen, so ergäbe sich für die hohe Zange nur eine Mortalität. von $14,0 \mathrm{pCt}$.)

$\mathrm{Zu}$ berücksichtigen ist bei diesem Ergebnisse aber noch, dass 2 von den Kindern, die die nächsten Wochen oder Yonate nach der Geburt am Leben blieben, von Anfang an krank waren, und dass bei dem einen Falle (Fall Kiel) sicher, in dem anderen (Fall Schneider) wenigstens möglicherweise die Ursache der Erkrankung in dem durch die Zange erlittenen Geburtstrauma lag. In beiden Fällen war die Vornahme der Entbindung durch die Gefahr einer drohenden Uterusruptur strict indicirt gewesen:

1) Nage I, 1. c. und: Weitere Beobachtungen über die Anwendung der Achsenzugzange. Dieses Archiv. Bd. 44. 1893. - Centralbl. f. Gynäk. 1892. No. 17.

2) Das Kind wurde nach vergeblichem Zangenversuch und Perforation mit deutlichen Zeichen der intrauterinen Leichenstarre geboren. Herztöne waren schon vor Anlegung der Zange nicht mehr zu hören gewesen. (Fall Qualitz. Journ. No. 324. Jahrgang 1901/2.) - (Vergl. Bruno Wolff, Ueber intrauterine Leichenstarre. Dieses Archiv. Bd. 68. 1903. Fall 3). 
1. Fall Kiel (Journ.-No. 491, Jahrg. 1898/99): Rachitisch plattes Becken: Spinae 28, Cristae 29, Conj. ext. 18, Conj. diag. ca. $11 \mathrm{~cm}$. Die ersten 3 Geburten verliefen angeblich normal.

31 jährige IV para. 1. Schädellage. 20 Stunden nach dem Blasensprung: Unteres Uterinsegment auf Druck schmerzhaft. Contractionsring. Blutiger Urin. Pat. hat seit 2 Tagen heftige Schmerzen im linken Bein. -

Kindliche Herztöne 176. Kopf im Beckeneingang. Promontorium mit gekrümmtem Finger zu erreichen.

Hohe Zange.

Atonische Nachblutung. Manuelle Placentarlösung. Leicht asphyktisches, wiederbelebtes Kind.

Wochenbett: Nach der Futbindung entwickelte sich eine Neuritis im linken Bein und eine linksseitige parametritische Resistenz. Fieber. Aufnahme in die Klinik; dort baldige Entfieberung und allmähliche Genesung.

Eine an 12. Mai 02 vorgenommene Nachuntersuctrung ergab: Das Bein ist vollkommen wiederbergestellt; jedoch klagt die Patientin" seit der Entbiudung über Unterieibsbeschwerden. Damm intact. Portio dick. Uterus anteflectirt, etwas dick und derb. Hinteres Scheidengewölbe resistent. Narbiger Strang im rechten und im linken Parametrium. Hängebauch. Diagnose: Parametritis chronica.

Was nun den weiteren Verlauf für das Kind anbetrifft, so erkrankte dasselbe bald nach der Geburt an Krämpfen. Am 3. Tage wurde das Kind in die Säuglingsabtheilung der Charité aufgenommen.

Herr Privatdocent Dr. Finkelstein, der den Fall beobachtete, hat die Krankengeschichte des Kindes in einer Arheit über ndie durch Geburtstraumen hervorgerufenen Krankheiten des Säuglings"1) ausführlich berichtet. Ich hebe aus der von diesem Autor gegebenen Schilderung hervor, dass bei der Anfnalume des Kindes Coma, leichte Parese und spastische Erscheinungen in den Extremitäten, linksseitige Facialisparalyse, Icterus und Fieber bestanden. Ausserclem waren schwere Spuren der Zangenlöffel bemerkbar; der linke Bulbus war zerquetscht. Häufig traten eigenartige Krämpfe auf. Im. Alter von drei Wochen wurde das Kind ,scheinbar völlig hergestellt entlassen, alle Lähmungen und Reizerscheimungen geschwunden." Der Fall wurde aufgefasst, als peripherische linksseitige Facialislähmung, combinirt mit Meningealblutung über der linken Hemisphäre. Icterus und Fieber wahrscheinlich durch Resorption des Extravasates bedingt:" Spätere Nachfrage über das Kind ergab, „dass die Besserung eine trügerische war. Nach der Entlassung stellten sich sehr bald maximale Flexionscontracturen aller 4 Extremitaten, Opisthotonus und Zwangshaltung des Kopfes nit über der rechten Schulter stehendem Kinne ein. Dabei wahrscheinlich Idiotie. Tod im 3. Monat. Keine Section."

2. Fall Schneider (Journ.-No. 859, Jahrg. 1900/01): Rachitisch plattes Becken: Spinae 271/2, Cristae 28, Conjugata externa 16, Conj. diagon. 9-91/2 cm. Rachitiseher Rosenkranz. Kyphoskoliosis dorsalis mit Lordosis lumbalis.

1) Finkelstein, Berliner Klinik. H. 168. Juni 1902. Seite 7, 8 u. 11. 
Frühere Geburten:

1. Geburt: Frühgeburt, spontan, todtes lind.

2. Geburt: normal, spontan, lebendes Kind.

3. Geburt: Schädellage mit Nabelschnurvorfall. Wendung und Extraction (Geburtsh. Poliklinik der Charité).

4. Geburt: 2. Schädellage. Vorliegende Nabelschnur. Wendung bei stehender Blase und vollstandig erweitertem Nuttermund. Extraction. Lebender Knabe. (Geburtsh. Poliklinik der Charite.)

5. Geburt: Schärellage. Vergeblicher Versuch mit der hoben Zange. Kraniotomie. (Geburtsh. Poliklinik der Charité.)

Jetzt: 33 jährige VI-para. 2. Schädellage.

$151 / 2$ Stunden nach dem Blasensprung: Contractionsring mehr als handbreit oberhalb der Symphyse. Temperatur 38,00. Kindliche Herztöne 168. Kopf ziemlich mit dem grössten Durchmesser fest im Beckeneingang. Muttermund vollständig erweitert.

Sehr schwierige Extraction mit der Achsenzugzange. Lebendes reifes Kind.

Wochenbett: bis auf vorübergehende Erscheinungen einer Neuralgie in einem Bein normal.

Eine am 7. Juni 1901 vorgenommene Nachuntersuchung ergab: Patientin ist vollkommen wohl; am Bein ist nichts Pathologisehes nachzuweisen. Mässiger Descensus vaginae. Uterus anteflectirt, ziemlich klein. Ovarien descendirt, Adnexe im Uebrigen ohne Besonderheit. Kleiner, rechtsseitiger Cervixriss. Mässiger Grad von Hängebauch. -

Das Kind erkrankte schon in den ersten Tagen nach der Geburt mit spastischen Erscheinungen an den Gliedmaassen. Diese Symptome verschwanden allmählich. 1/4 Jahr später wird ein hoch gradiger Hydrocephalus festgestellt. (Bei der Geburt war keine Spur eines Hydrocephalus wahrzunehmen gewesen.) Das Kind blieb wollkommen dement und starb innerhalb der ersten 6 Lebensmonate. -

In dem letzteren dieser beiden Fälle ist es allerdings nicht ausgeschlossen, dass es sich um einen von dem Trauma unabhängigen Hydrocephalus gehandelt hat; immerhin aber ist die Möglichkeit vorhanden und durchaus in Betracht zu ziehen, dass ein Geburtstrauma bei der schwierigen Zangenextraction erst die Veranlassung zur Entstehung des Wasserkoples gegeben habe ${ }^{1}$ ). -

Den weiteren Einzelheiten nach gestalteten sich die bei Anlegung der Zange an den hochstehenden Kopf für die Kinder erzielten Resultate folgendermaassen:

1) In seiner oben citirten Arbeit kommt Finkelstein zu dem Schluss, "dass Geburtstraumen sowohl durch directe Läsion der Hirnsubstanz selbst oder mittelbar durch eine Blutung mit folgender Circulations- und Ernährungsstörung oder anschliessende Pachymeningitis, Hydrocephalus externus und vor Allem ehronische Meningoencephalitis die Ursache ernster, bleibender Gehirnschädigung werden können". 
Mittelst der bohen Zange wurden geboren:

In 1. Schädellage: 30 Kinder mit 3 todten $=10,0$ pCt., "2. $n \quad 25 \quad " \quad 5 \quad=25,0 "$; ausserdem in (fraglich ob 1. oder 2.) Schädellage: 1 lebendes Kind.

INB. In 2 von diesen Fällen war ursprünglich eine Hinterscheitelbeineinstellung vorhanden, die manuell corrigirt wurde, zweimal eine Stirnlage, die vor der Zangenanlegung manuell in Hinterhauptslage umgewandelt worden ist.

Ferner: In 1. Schädellage mit Nabelschnurvorfall: 1 lebendes Kind.

Die Zange wurde vergeblich versucht.

Bei 1. Schädellage: $2 \mathrm{Mal}$ "2. bezw. $3 . \quad n \quad 8 n$

2. Stirnlage: $2 n$ $2 "$
1 Bei 2. Schädell. m. Nabelschnurvorfall: 1 , stets todte

Lassen wir das durch Nabelschnurvorfall gestorbene und das bereits vor Anlegung der Zange todte Kind unberücksichtigt, so kamen auf:

13 hohe Zangen bei

I-paris: 5 todte Kinder $=38,4$ pCt.

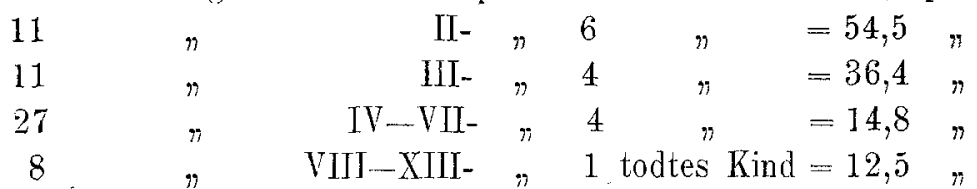

Im Ganzen:

57 hohe Zangen bei Mehrgebärenden: 15 todte Kinder $=26,3 \mathrm{pCt}$.

Dem Becken nach batten wir unter den hohen Zangen:

$$
\text { Platte Becken: }
$$

Conjugata vera: $93 / 4-9 \mathrm{~cm}: 20$ Kinder mit 4 todten $=20 \mathrm{pCt}$.

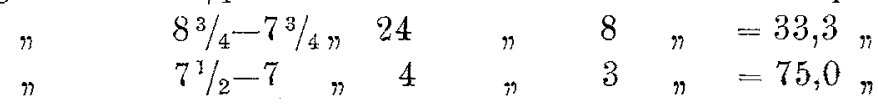

Allgemein verengte Becken:

Conjugata vera: $93 / 4-9 \mathrm{~cm}$ : 5 Kinder mit 0 todten $=0$ pCt. $" 8 \frac{3}{4}-73 / 4,17 " 5 n=29,4 n$ Bemerkenswerth ist, dass das einzige Kind, das bei einer Conjugata vera unter $7 \frac{3}{4} \mathrm{~cm}$ mit der hohen Zange lebend zur Welt befördert wurde, dasjenige war, das, wie oben erwähnt 
264 Wolf, Weiterer Beitrag zur Therapie der Geburt beim engen Becken.

(Fall Sohneider), kurz nach der Geburt ar Krämpfen erkrankte und an Hydrocephalie zu Grunde ging.

Sehr verschieden gestalteten sich die Resultate fü die Kinder je nach den verschiedenen Indicationen zur Anlegung der bohen Lange:

a) Die 11 Fälle, in denen die Indication zur Entbindung nur rom Kinde ausging, ergaben: 10 lebende und 1 todtes Kind (Tod durch Nabelschnurvorfall). (Mortalitat: 9,1 pCt.)

b) Die 21 Fälle, in denen die Indication zur Entbindung nur von der Mutter ausging, ergaben: 12 Jebende und 10 todte Kinder. (Mortalität: 47,6 pCt.)

c) Die 39 Fälle, in denen eine Indiration zur Entbindung sowohl von Seiten der Mutter wie von Seiten des Kindes vorlag, ergaben: 28 lebende und 11 todte Kinder, (Mortalitat: 28,2 pCt.)

Wir kommen nunmehr zu dem Ergebniss der hohen ZangenOperationen für die Mütter:

Nach den 71 Geburten kam 1 Todesfall urd zwar an Sepsis vor. Die betreffende Patientin hatte schon während der Entbindung gefiebert:

Fall Heuer (Polik]. Journ.-No. 218, Jahrg. 1901/02): Rachitiseh plattes Becken: Spinae 271/2, Oristae 29, Conj. ext. $18 \% / 2$, Conjugata diagon. $11 \mathrm{~cm}$.

Fr ühere Gebarten:

1. Goburt: Angeblich spontan.

2. Geburt: Wegen Ausziebung des unteren Uterinsegmentes vergeblicher Versuch mit der hohen Zange, dann Kraniotomie (Geburish. Poliklinik der Charité).

3. Geburt: Wegen Ausziehung des unteren Uterinsegmentes hohe Zange. Lebender; $53 \mathrm{~cm}$ langer Knabe. (Geburtsh. Polikl. der Charité.)

Jetzt: 32 jührige IV para. 2. Schädellage.

Circa 3 Tage nach dem Blasensprung: Tetanus uteri. Teinperatur $38,8^{\circ}$. Puls 110 .

Kindliche Herztöne 160.

Ein kleiner Theil des Kopfes steht im Beckeneingang. In Narkose und Walcher'scher Hängelage gelingt es, den kopf von aussen soweit in das Becken hineinzudrücken, dass das Promontorium nur noch mit gekrümmtem Finger zu erreichen ist.

Achsenzugzange.

$53 \mathrm{~cm}$ langes, $4120 \mathrm{~g}$ schweres, Lebendes Mädchen, das nach $48 \mathrm{Std}$. virbt. Wochenbett: fieberbaft; schliesslich Exitus letalis an Sepsis.

Fieber mit Ausgang in Genesung wurdo nach 12 Geburten beobachtet.

3 Patientimnen erkrankten im Wochenbett an einer Neuritis des einen Beines. Bei rweien von diesen wurde Genesung fest- 
gestellt; bei der dritten hatte sich der Zustand bis zur Entlassung aus der Beobachtung allmählich gebessert.

Von Verletzungen, die bei der Operation zu stande kamen, sind zu erwähnen:

Dammincisionen: $2 \mathrm{mal}$.

Dammrisse 1. Grades: 3 mal.

Dammrisse 2. Grades: 4 mal.

Incisionen in den Muttermund: 2 mal. -

Der vorstehenden Uebersicht über unser Material an Zangenoperationen bei engem Becken habe ich folgende Bemerkungen hinzuzufügen:

„Nur grobe Unkenntniss der gesammten Verhältnisse und Mangel an Urtheil in geburtshülffichen Dingen", schreibt Olshausen, ${ }^{1}$ ) "hat einige Autoren dazu veranlasst, Wendung und Zange beim engen Becken einander gegenüber zu stellen. Spiegelberg, Fuhrmann und Schröder haben diesen groben Trrthum geburtshülflicher Ansehauungsweise genügend zurückgewiesen. Erfolgt die Geburt in Kopflage und ändern wir diese Lage nicht durch die Wendung, so haben wir stets die spontane Geburt durch die verengte Stelle im Auge zu behalten, zur Zange nur in seltenen Fällen, unter besonderer Reserve zu greifen".

Auf diesen Standpunkt haben sich auch die Autoren, die sich in neueren Arbeiten über die Indicationsstellung zur Zange beim engen Becken geäussert haben, gestellt (Münchmeyer ${ }^{2}$ ), $K_{n}$ ap $p^{3}$ ), Ludwig und Savor ${ }^{4}$ ), Krönig ${ }^{5}$.

Entsprechend den Lehren Gusserow's ist auch bei unserem Material ron einer Zange wegen engen Beckens nje die Rede gewesen.

Wenn wir eine ziemlich grosse Anzahl von Zangenoperationen aufzuweisen haben, so kann hier immer nur von einer Zange bei engem Becken, nie von einer Zange wegen engen Beckens gesprochen werden.

1) Olshausen, Lehrbuch der Geburtsbülfe. 1902. S. 527.

2) Münchmeyer, Ueber die Entbindungen mittelst der Zange an der Kgl. Frauenklinik in Dresden. Dieses Archiv. Bd. 36. 1889.

3) Knapp, Bericht über 105 Geburten bei engem Becken. Dieses Archiv. Bd. 51. 1896.

4) Ludwig und Savor, 1. c. S. 182.

5) Krönig, l. c. 
Nicht das enge Becken hat die Indication zur Zangenanlegung abgegeben; vielmehr sahen wir in Uebereinstimmung mit'dem beKannten Ausspruche 0lshausen's ${ }^{1}$, dass die Zange ,für das enge Becken im Allgemeinen wie die Faust auf's Auge" passe, das enge Becken eher als eine Contraindication gegen den Forceps an. -

Trotzdem aber wurde vielfach die Zange angewendet, wemn besondere Umstände die Beendigung der Geburt erheisehten und die Rettung des Kindes möglich erschien. Als solche besonderen Umstände galten nur gefahrdrohende Symptome, die im Befinden der Mutter oder des Kindes nachweislich eingetreten waren. Wehenschwäche allein wurde nicht als genügender Grund zur Anlegung. des Forceps erachtet.

Bei dieser Indicationsstellung ist das enge Becken direct mithin niemals, indirect dagegen häufig die Veranlassung zur Zangenoperation gewesen, indem es den Geburtsverlauf verzögert und zu Störungen geführt hatte. -

Ueberblicken wir nun zunächst das Ergebniss der 90 Zangenoperationen, die bei engem Becken und in der Beckenweite oder noch tiefer stehendem Kopfe ausgeführt wurden:

Die Mortalität der Kinder betrug hier nur 5,6 pCt.; der Procentsalz der todtgeborenen Kinder war für die Erstgebärenden um oin Geringes grösser als für die Mehrgebärenden $(6,0 \mathrm{pCt}$. bei Iparis gegenüber $4,5 \mathrm{pCt}$. bei letzteren). -

Für die Mütter war das Tirgebniss quoad vitam ein absolut gutes. In den keiden Fällen, in denen schwerere Verletzungen (Dammrisse 3. Grades) zustandekamen, handelte es sich um Zangenoperationen, die bei tiefstehendem Kopfe aus Indicationen, wie sie sich auch bei normalem Becken bei Primiparis hänfig einstellen, ausgeführt werden mussten.

Diese Resultate sind jedenfalls als recht günstige zu bezeichnen. v. Winckel2) schreibt: „In München gebrauchten wir in 7.Jahren bei 5993 Geburten $157 \mathrm{mal}$ den Forceps, also in 2,6 pCt. aller Geburten; von diesen Frauen unterlagen $3=1, y$ pCt., von den Kindern wurden todtgeboren und unterlagen noch im Ganzen $26=16$ pCt., während unter 8297 Kreissenden der sämmtlichen preussischen Kliniken in den Jahren $1887-89: 392=3,4$ pCt. mit

1) Olshasen, 1. c. S. 530 .

2) $\because$ Winckel, Lehrbuch der Geburtshülfe. 1893. S. 661 . 
der Zange entbunden wurden, von denen $17=4,4$ pCt. Mütter und $52=17,8$ pCt. Kinder starben." -

Die bei mindestens in die Beckenweite eingetretenem Kopfe ausgeführten Zangen bieten also nach unseren Erfahrungen (vorausgesetzt natürlich, dass die sonstigen Bedingungen zur Zangenoperation erfüllt sind), beim engen Becken keine besonderen Gefahren dar. Unter diesen Umständen darf mithin die Zange, auf die für dieselte im Allgemeinen gültigen Indicationen hin, bei engerr Becken in gleicher Weise wie bei normalem angelegt werden. -

Wichtiger ist die Betrachtung der mit der hohen Zange erzielten Resultate:

Die Gesammtmortalität der Kinder betrug bei sämmtlichen 71 Fällen, bei denen die hohe Zange an'gelegt wurde, 29,0 pCt, (bei denen, bei welchen sie zu Ende geführt wurde, 14,0 pCt.)

Eine Gegenüberstellung der Resultate, die wir aufzuweisen, und derjenigen, die andere Autoren mit der hohen Zange erzielt haben, ist kaum angängig, da die Indicationsstellung eine zu verschiedene ist und der Begriff der hohen Zange nicht gleichmässig. gebraucht wird. Auch ist in vielen Arbeiten über diesen Gegenstand das Ergebniss der vergeblichen Zangenversuche nicht mit in Anrechnung gebracht worden.

Immerhin sei erwähnt, dass nach Braun v. Fernwald ${ }^{1}$ ) unter 78 "atypischen" Zangenoperationen bei engem Becken 12,8 pCt. todte Kinder zur Welt kamen.

Münchmeyer ${ }^{2}$ ) berichtet, dass von 19 durch die hohe Zange entwickelten Kindern 4 starben $=21$ pCt. -

Sucht man nun zu einem Urtheil über den Werth der bohen Zange zu gelangen, so muss man sich zunächst fragen, ob man die mittelst der hohen Zange erzielten Resultate in Vergleich mit denen bei einem anderen, in diesen Fällen mit der hohen Zange concurrirenden Verfahren stellen und auf diese Weise zu einem Schlusse gelangen kann:

Kaiserschnitt und Wendung kommen in dem Stadium der Geburt, um das es sich bei dem hohen Forceps handelt, nicht in Betracht.

1) Citirt nach Münchmeyer.

2) I ünchmeyer 1.c. 
268 Wolff, Weiterer Beitrag' zur' 'Therapie der Geburt beim engen Becken.

Die Kraniotomie kann nur in ihren Lirfolgen für die Hutter der hohen Zange gegenübergestellt werden. Für diejenigen Fälle, in denen der hohe Forceps nur im Interesse des Kindes angelegt wurde, ohne dass von Seiten der Mutter eine stricte Indication zur Entbindung vorlag, kam die Kraniotomie als Coneurrenzoperation überhaupt nicht in Frage.

Ebensowenig wäre ein Vergleich mit den Erfolgen spontan verlaufener Geburten berechtigt; denn in vielen Fällen, in denen die Extraction mit der hohen Zange ausgeführt oder wenigstens versucht wurde, konnte von einem weiteren Abwarten aui den spontanen Verlauf gar nicht die Rede sein, weil ein dringender Anlass, die Geburt im Interesse der Mutter sofort zu beenden, vorlag.

Dasjenige Eutbindungsverfahren, mit dem man die Resultate der hohen Zange noch am ehesten in Verglejch setzen könnte, wäre die Symphyseotomie. Hinsichtlich dieser Operation wäre bei einem solehen Vergleich aber Folgendes in Betracht zu ziehen:

Zweifel ${ }^{1}$ ) berichtet über die Resultate seiner Symphysiotomien, dass auf 46 Operationen 3 Todesfälle $(=7 \mathrm{pCt}$.) kamen, wobei alle Fälle mit eingerechnet sind. Bei der hohen Zange dagegen hatten wir in der Poliklinik unter 71 Operationen nur 1 Todesfall $(=1,4$ pCt.). Dieser eine Todesfall, der durch Sepsis eintrat, betraf eine Kreissende, die schon vor Anlegung des Forceps fieberte. - Allerdings gelang es $Z$ weifel ${ }^{1}$ ) durch die von ihm vervollkommneto Technik der Symphyseotomie neuerdings, seit der Einführung der Troicar-Drainage durch die Scheide, fieberfreien Verlauf des Wochenbettes nach der Symphyseotomie zu erzielen, sodass dic zukünftigen Erfolge des Schamfugenschnittes weit bessere als die früheren zu werden versprechen. (Krönig²) giebt in einer kürzlich erschienenen Arbeit die Mortalität der Symphyseotomie nur noch auf 2 pCt. an.)

Wie dem aber auch sei: bisher ist jedenfalls nicht bewiesen, dass ähnliche Erfolge wie in der Klinik mit der Symphyseotomie auch in der Poliklinik erreicht werden können. -

1) Zweifel, Die Symphyseotomie mit besonderer Drainage des Spatiun praevesicale sive Carum Retzii per vaginam. Beitr. zur Geburtsh. und Gynäli. Bd. 6. 1902 .

2) Krönig, Geburtsleitung beim engen Becken. Münchener medicin. Wochenschr. 1902. No. 32. 
Wenn mir dies vorläufig zweifelhaft erscheint ${ }^{1}$ ), so habe ich hierbei nicht etwa in erster Linie die grössere Schwierigkeit der Technik im Auge; viel wichtiger ist ein anderer Umstand:

Zweifel2) selbst betont, dass bei der Symphyseotomie wie beim Kaiserschnitt. Fruchtwasserfäulniss eine viel ernstere Bedeutung hat, als etwa bei einer Zangenoperation odur bei einer Perforation. Auch Meng $\mathrm{e}^{3}$ ) wies auf die ungünstigen anatomischen Verhältnisse der bei der Symphyseotomie gesetzten retrosymphysären Höhlenwunde hin.

Die 71 Entbindungen nun, bei denen in der Poliklinik der Charité die hohe Zange angelegt worden ist, betrafen vieliach Frauen, zu denen der Arzt erst in einem vorgeschrittenen Stadium der Geburt gerufen wurde, und fast alle oder vielleicht alle Kreissende waren vor Anwesenheit des Arztes von der Hebamme innerlich untersucht worden. Diese Zustände zu ändern liegt vorläufig nicht in unserer Macht. Eine Garantie dafür, dass die Aseptik während der Entbindung in dem Maasse gewahrt wurde, wie es gerade speciell für die Vornahme der Symphyseotomie nothwendig ist ${ }^{4}$, kann man unter diesen Verhältnissen natürlich nicht annähernd so sehr übernchmen, wie in einer Klinik, wo von Anfang an alle Vorsichtsmaassregeln unter gewissenhafter Controlle aufrecht erhalten worden sind. -

Aus diesen Gründen bleibt anzumehmen, dass man unter Bedingungen, wie sie unsere 71 hier in Rede stehenden Entbindungen mit der hohen Zange darboten, durch selbst mit vollendeter Technik ausgefürte Symphyseotomien bei weitem nicht so günstige

1) Leopold (Ueber die Symphyseotomie und ihre Indicationsstellung. Centralblatt für Gynäliologie. 1894) und Veit (Ueber den Kaiserschnitt aus relativer Indication. Beiträge zưr Geburtsh. u. Gynäk. Bd. 4. S. 328. 1901) haben anf den Unterschied, der hinsichtlicb der In dicationstellung zur Symphyseotomie zwischen Klinik und allgemeiner Praxis besteht, ebenfalls hingewiesen. - Hofmeier sagt in einer vor Kurzem erschienenen Abhandlung (Ueber die Berechtigung der Perforation des lebenden Kindes. Zeitschrift für Geburtsh. und Gynäk. Bd. 48. 1903), die Symphyseotomio sei ,keine Operation für die Praxis".

2) Zweifel, I. c.

3) Menge, Centralblatt f. Gynäk. 1901. S. 681.

4) Selbstverständich gilt dies in noch höherem Maasse für den Kaiserschnitt. Siehe im folgenden die Vorsichtsmaassregeln, die Veit vor dieser Operation beobachtet. 
270 Wolff, Weiterer Beitrag zur Therapie dor Geburt beim engen Becken.

Resultate für die Mütter wie mit der hohen Zange hätte erzielen können. -

Noch ein Punkt ist, wenn man hohe Zange und Symphyseotomie in Vergleich mit einander stellen will, zu bedenken:

Selbst ein so eifriger Verfechter der Symphyseotomie, wie Krönig1), will diese Operation nicht ausführen, wenn bei platten und platt rachitischen Becken mit einer Conj. vera über $7 \mathrm{~cm}$ und bei den mehr allgemein verengten mit einer Conj. vera über $71 / 2 \mathrm{~cm}$,eine Gefahr für Mutter oder Kind schon eingetreten" ist. Er stellt die Indication zur Symphyseotomie dann, "wenn eine längere Beobachtung des Geburtsverlaufs mit grösster Wahrscheinlichkeit einen günstigen Ablauf für Mutter und Kind bei spontaner Geburt ausschliesst"; „dabei soll aber im allgemeinen nicht so lange gewartet werden, bis Mutter oder Kind sehon in Gefahr" geriethen. -

Ganz im Gegentheil legen wir die hohe Zange principiell nicht eher an, als bis nachweislich Störungen im Befinden der Mutter ader des Kindes vorhanden sind. -

Es giebt nun in der Praxis genug Fälle, zu denen der Arzt erst gerufen wird, nachdem eine Gefahr für Mutter und Kind bereits aufgetreten ist. Es wird sich zuweilen auch ereignen, dass bei dem abwartenden Verfahren, wie es Krönig vor der Symphyseotomie befolgt, unvorhergesehen schnell im Befinden der Mutter oder des Kindes sich Störungen bemerkbar machen.

Für alle diese Entbindungen also käme die Symphyseotomie schliesslich nicht mehr in Betracht, während gerade dann zu erwägen wäre, ob durch die hohe Zange noch ein günstiger Ausgang für Mutter und Kind erzielt werden kann. --

Ein Urtheil über den Werth der hohen Zange lässt sich mithin, jedenfalls was die Verhältnisse in der Polik]inik und in der allgemeinen Praxis anbetrifft, nicht auf Grund eines einfachen Zahlenvergleichs zwischen den Resultaten der hohen Zange und den Erfolgen eines mit derselben concurrirenden Entbindungsverfahrens ahgeben.

Wohl aber kaun man zu einem Urtheil über den Werth der hohen Zange auf Grund der folgenden Erwägungen gelangen:

1) Krönig, Die Therapie beim engen Becken. Jueipzig 1901. S. 201 und 202 . 
Ziehen wir zunäehst die Erfolge der Operation, lediglich soweit es sich um die Kinder handelt, in Betracht:

In nahezu dem fünften Theil unserer Beobachtungen gelang es nach der Anlegung der Zange an den im Beckeneingang stehenden Kopf nicht, das Kind mit dem Forceps durch das Becken zu ziehen. Die Operation hatte mithin sehr häufig keinen Erfolg.

Die Anwendung der hohen Zange ist daher unter allen Umständen nur als ein Versuch anzusehen, dessen Gelingen man nicht mit Sicherhoit voraussehen kann.

Dieser Versuch ist aber von grosser Bedeutung: Wenn er misslingt, so muss man, wie wohl allgemein anerkannt wird, sich fast immer, im Hinblick auf die Gefahren einer längeren Dauer der Geburt nach einem derartigen, stets mit Quetschungen der mütterlichen Weichtheile verbundenen Eingriffe zur Kraniotomie entschliessen. -

Auch wenn aber die Anwendung der Zange erfolgreich ist, d. h. wenn es obne schwere Schädigung der Mutter glückt, das Kind mit dem Forceps zur Welt zu befördern, - wird durch die Operation nicht ganz selten der Tod oder wenigstens eine erhebliche Verletzung des Kindes herbeigeführt. -

Es ist nun aber, soweit es sich um das Kind handelt, ganz klar, dass weder die Möglichkeit des Misslingens der Operation und der hierauf nothwendigen Kraniotomie, noch die Möglichkeit einer schweren Verletzung des Kindes einen Grund gegen die Anlegung der Zange abgeben kann, wenn ohne einen solchen Versuch zur Rettung des Kindes dasselbe mit Sicherheit oder allergrösster Wahrscheinlichkeit verloren wäre.

Das trifft für zwei Fälle zu:

Erstens dann, wenn der Zustand der Mutter strict die Entbindung fordert und nur die Wahl zwischen Zange und sofortiger Perforation besteht; $z$ weitens unter Umständen, wo die Wahl zwischen weiterem Abwarten und hoher Zange bliebe, das $A$ bwarten aber mit Sicherheit oder allergrösster Wahrscheinlichkeit den Tod des Kindes herbeiführen müsste; z. B. wenn der Kopf soeben fest in das Becken eingetreten und die Nabelschnur vorge fallen ist.

Unter solchen Umständen, - und so war es in einer grossen Anzahl der von uns mit der hohen Zange behandelten Geburten, - kann gar kein Zweifel darüber bestehen, dass einer glücklich ausgeführten Zangenoperation allein die Lebensrettung des Kindes 
zu verdanken sei, eine misslungene aber für das Kind jedenfalls bedeutungsios ist. - Mag man daher die Mortalitätsziffer bei unseren Fällen als eine grosse oder kleine ansehen, der überwiegend häufig erreichte glückliche Ausgang beweist, wie segensreich unter den genannten Indicationen die hobe Zange zu wirken vermag. -

Ganz anders aber liegen die Dinge, wenn der Zustand der Mutter kein gefahrdrohender und die Gefahr für das Kind bei weiterem Abwarten keine so ersichtliche und momentane wie beim Nabelschnurvorfall ist, wenn vielmehr nur aus der abnormen Frequenz der kindlichen Herztöne und dem Abgang von Meconium auf Störungen im Befinden des Kindes geschlossen wird, die baldige Beendigung der Geburt somit allerdings mit Recht erwünscht erscheint.

Hier stent die Gefahr des weiteren Abwartens den Gefahren gegenüber, die die hohe Zange, - sei es, dass sie gelingt oder dass sie nicht gelingt, - für das Kind einschliesst.

Allerdings haben wir bei unserem Material ein besonders gutes Resultat gerade in jenen Fällen erzielt, wo eine Beendigung der Geburt nur von Seiten des Kindes indicirt war. Jedoch dürften sich wohl die Operateure hier ganz naturgemäss im Allgemeinen erst bei verhältnissmässig günstigem Stande des Kopfes zur Zangenanlegung entschlossen haben; bei Störungen im Befinden der Mutter wurde dagegen, da die schnelle Entbindung der Kreissenden dann viel stricter angezeigt war, auf den Stand des Kopfes weniger Rücksicht genommen.

Meiner Ueberzeugung nach handelt man in solchen Fällen, wo aus dem allmählichen Steigen oder selbst Sinken der kindlichen Heratöne und dem Abgange von Meconium eine Gefahr für das Kind ersichtlich ist, fast immer am richtigsten, wenn man sich dennoch nicht eher, als bis der Kopf etwa in die Beckenweite gekommen ist, zum Anlegen des Forceps entschliesst.

Die Gründe für diese Anschauung liegen erstens darin, dass, wie besprochen, nicht nur das Abwarten, sondern ebenso auch die hohe Zange für das Kind, und besonders für ein nicht mehr ganz lebenskräftiges Kind, grosse Gefabren mit sich bringt.

Zweitens aber ist man meist garnicht im Stande, zu sagen, ob die Frucht nicht trotz der genannten, in ihrem Befinden zu 
constatirenden Störungen doch bei abwartendem Verhalten noch wiele Stunden lang völlig lebenskräftig bleiben wird. ${ }^{1}$ )

Einen recht anschaulichen Beweis für diese Möglickeit gab mir eine Beobachtung, in der ich trotz erheblicher Verlangsamung der kindlichen Herztöne und trotz Abganges von Meconium bei noch hochstehendem Kopfe $121 / 2$ Stunde lang abgewartet und erst, als der Kopf in die Beckenweite gelangt war, die Zange angelegt habe. Das Kind kam lebend zur Welt. Ein auf Grund der für die Frucht schon lange festgestellten Lebensgefahr bei noch hochstehendem Kopfe ausgeführter Eingriff hätte hier vielleicht den Tod des Kindes herbeigeführt:

Fall Orth (Journ.-No. 507, Jahrg. 1900/01.): 31 jährige II para. Allgemein verengtes Becken: Spinae 24, Cristae 271/2, Trochanteren $301 / 2$, Conjug. ext. $171 / 2$, Conjug. diag. $10^{1 / 2} \mathrm{em}$.

12. 11. 1900: 3 Uhr Nachmittags Blasensprung. 13.11. um $1 / 211 \mathrm{Ubr}$ Yormittags wird poliklinische Hälfe hinzugezogen. - 1. Schädellage. Der Kopf steht erst mit einem kleinen Segment im Beckeneingang. Kindliche Herztöne 90. Es gebt massenhaft Meconium ab. Da dảs Promontorium noch mit geradem Finger zu erreichen ist und von Seiten der Mutter keine Indication zur Entbindung vorliegt, so wird abgewartet. Es fliesst während der ferneren Beobachtung weiter Meconium in sehr grosser Menge ab. Um 11 Uhr Abends steht der Kopf in der Beckenweite. Temp. $37,4^{0}$, Puls 108 . Kindliche Herztöne unregelmässig. Nunmehr wird die Zange angelegt und selbst jetzt nur mit ziemlich grossen Schwierigkeiten ein tief asphyktisches, $53 \mathrm{~cm}$ langes Mädchen extrahirt. Das Kind wird wiederbelebt und bleibt am Leben. Wochenbett normal.

Wir kommen also nach den bisherigen Ausführungen, bei denen die Prognose der hohen Zange nur im Hinblick auf das Kind berücksichtigt ist, zu dem Schluss, dass die Operation nur dann vorzunehmen, bezw. zu versuchen sej, wenn eine stricte Indication zur Entbindung von Seiten der Mutter vorliegt oder wenn bei weiterem Abwarten das Kind mit aller Sicherheit verloren wäre. -

Es bleibt aber noch zu erörtern, ob etwa die Gefahren, die der bohe Forceps für die Mütter darbietet, eine noch grössere Einschränkung im Gebrauch der hohen Zange vorschreiben. - Die Resultate für die Mütter waren nun die folgenden:

1) Aehnlich hat sich in dieser Beziehung kürzlich Krönig (Münchener med. Wochenschr, 1902. No. 32) ausgesprochen. - Zweifel (Lchrbuch der Geburtshilfe. 1895. S. 570) hat die hohe Zange bei "allen Indicationen von Seiten des Kindes' für unstatthaft erkärt. - Auch Nagel (Operative Geburtshilfe. Berlin 1902. S. 230) räth, bei Indication von Seiten des Kindes, wenn der Kopf noch hoch steht, das Kind seinem Schicksal zu überlassen. 
274 Wolff, Weiterer Beitrag zur Therapie der Geburt beim engen Becken.

Nach den 71 kntbindungen lkam, wie besprochen, nur ein Todesfall an Sepsis bei einer Frau, die schon vor der Operation fieberte, vor. Die Anzahl der Verletzungen der Mütter war eine sehr geringe; fast stets handelte es sich nur um verhältnissmässig unbedeutende Risse. -

Trotz dieser Erlolge können gewiss die Gefahren eines rohen, bei noch über dem Becken stehendem Kopfe unternommenen oder forcirten Zangenversuches nicht genug gefürchtet werden. Die schweren Verletzungen, die die Mütter bei derartjgen Operationen erlitten haben, führten mit vollem Recht zur Verwerfung aller Zangenoperationen, die wegen des engen Beckens, um den Kopf durch die enge Stelle zu ziehen, ausgeführt werden sollten.

Die hohen Zangen und Zangenoperationen bei unserem Material haben mit derartigen Eingriffen nichts gemeinsam und könnten deshalb selbstverständlich nicht zur Rechtfertigung von solchen Operationen dienen, die in gan $z$ anderem Sinne und in ganz anderer Weise, als unsere, vorgenommen würden.

Andererseits aber muss man auf Grund unserer Resultate betonen, dass die hohe Zange, wenn sie in sachgemässer Weise ausgeführt und lediglich als ein Versuch ${ }^{1}$ ) betrachtet wird, für die Mutter keineswegs Gefahren darbietet, die ihre principielle Verwerfung irgendwie rechtfertigen würden. -

Dieses Ergebniss, zu dem wir gelangen, unterscheidet sich sehr wesentlich von der Meinung Münchmeyers²) über dje hohe Zange. "Wird", sagt dieser Autor, „unter solchen Verhältnissen" (- d. i. ,wenn zwar der Muttermund vollständig erweitert ist, der Kopf zwar tief, doch nicht so tief steht, dass er die Weichtheile des Beckens vollkommen ausgeglichen hat" _-) „die Zange angelegt, so ist man sicher, auch bei geschicktester und schonendster Operationsweise grosse, in vielen Fällen sogar

1) Ueber das Maass der Kraft, die bei diesem Versuch anfgewandt werden darf, lässt sich natürlich eine ganz bestimmte Vorschrift nicht geben. Mit Recht betonte $Z$ weifel (Lehrbuch der Geburtshülfe. 1895. S. 570) folgendes: Der Ausdruck „Versuch" gilt nicht der aufzuwendenden Kraft sondern der Unsicherheit des Erfolges; es wäre missverstanden, "wenn jemand unter dieser Bezeichnung verstehen will, dass man nicht stark ziehen dürfe". Andererseits stellt $Z$ weifel als Regel auf, cinen sehr grossen Widerstand nicht mit Gewalt zu überwinden und die Herztöne des Kindes fortwährend zu beobachten, weil diese den praktischen Druckmesser abgeben".

2) Münchmeyer, l. c. 
sehr grosse Zerreissungen der Scheide und des Dammes hervorzurufen". -

Dem ungünstigen Urtheil Münchmeyer's über die hohe Zange widersprechen jedoch ebenso wie die in der vorliegenden Arbeit berichteten Erfahrungen auch die älteren, von $\mathrm{Nagel}^{1}$ ) in der geburtshülflichen Poliklinik erzielten Resultate:

Nagel berichtete über seine Beobachtungen: "Von den 28 Yüttern, unter welchen 9 Erstgebärende waren, starb eine an acuter Sepsis, die fiebernd und mit einem Puls von 130, also bereits inficirt, in meine Behandlung gekommen war." Die übrigen ,27 Wöchnerinnen sind alle trotz zum Theil sehr schwerer Entbindungen genesen." An Verletzungen kamen vor: 7 mal ein Dammriss I. Grades, 4 mal ein Dammriss II. Grades, 2 mal ein kleinerer und grösserer Scheidenriss; „sämmtliche Verletzungen wurden sofort mit Seidenknopfnaht geschlossen uld heilten - abgesehen von dem Todesfalle - ohne den Verlauf des Wochenbettes zu beeinträchtigen, obwohl nicht alle per primam intentionem." "2)

$\mathrm{Zu}$ berücksichtigen sind beim Gebrauch der hohen Zange allerdings noch einige Punkte:

1. Der einzige Todesfall unter unseren 71 Operationen, der, wie erwähnt, eine bereits vor Anlegung der Zange fiebernde Mutter betraf (ebenso wie der einzige Todesfall in dem soeben besprochenen Material Nagel's), muss eine Warnung davor sein, die hohe Zange anzulegen, wenn deutliche Anzeichen einer septischen Infection vorhanden sind. In solchem Falle, wo alles darauf ankommt, Quetschungen und Verletzungen der Weichtheile nach Möglichkeit zu vermeiden, ist nur die Kraniotomie am Platze. -

2. Selbstverständlich muss vor Anlegung der hohen Zange der Muttermund in der gehörigen Weise erweitert sein, und es muss der Kopf fest stehen.

3. Selbstverständlich ist die hohe Zange dann nicht angebracht, wenn die Gefahr der Uterusruptur bereits eine hochgradige ist.

4. Die hohe Zange ist, wie auch $\mathrm{Nagel}^{3}$ ) betónt, keine Operation für den Ungeübten. Alles kommt auf die sachgemässe Ausführung und darauf an, dass die Extraction nicht forcirt, sondern nur als ein Versuch betrachtet wird, auf den beim Misslingen die Kraniotomie rechtzeitig folgen muss. -

1) Nagel, l. c. Dieses Archiv. Bd. 44. 1893.

2) Neuerdings theilt Nagel (Operative Geburtshülfe 1902, S. 221) mit, dass er unter 47 hohen Zangen in fortlaufender Reihe nur den Tod einer Mutter zo beklagen hatte.

3) Nagel, Operative Geburtshülfe. 1902. S. 224. 
Abgesehen aber von diesen Punkten, die im Auge zu behaiten sind, ergiebt sich keine Veranlassung, im Interesse der Nutter die Indicationen für den Versuch mit der hohen Zange noch mehr einzuschränken, als oben, wo nur die für das Kind aus der Anwendung der hohen Zange erwachsenden Gefahren in Betracht gezogen wurden, geschehen ist.

Die Gefahr beim Gebrauch der hohen Zange liegt, bei sachgemässem Operiren, mithin in erster Linie auf Seiten des Kindes. Es ist nothwendig, auf die für das Kind erzielten Resultate nochmals zurückzukommen, um noch einige specielle Verhältnisse in's Auge zu fassen:

Die Erfolge für die Kinder waren bei Mehrgebärenden im ganzen etwas besser als bei Erstgebärenden. Ganz besonders günstig aber waren sie bei Frauen, die schon mehr als dreimal geboren hatten. Es dürfte sich diese Thatsache durch den geringeren Widerstand, den die Weichtheile bei den späterer Geburten darbieten, erklären. -

Mit zunehmender Beckenenge verschlechtern sich die Ergebrisse für die Kinder sehr erheblich, sowohl bei den allgemein verengten wie bei den platten Becken. Bei einer Conjugata vera von $7 \frac{1}{2}-7 \mathrm{~cm}$ gelang es, unter allerdings nur 4 Beobachtungen, nur ein (später erkranktes) Kind lebend zur Welt zu befördern.

Von grösster Wichtigkeit für die Prognose ist zweifellos die Einstellung des Kopfes und die Grösse des Durchmessers, mit dem der Kopf in das Becken eingetreten ist. Eime statistische Zusammenstellung in Bezug auf diese Punkte zu geben, war leider bei dem poliklinischen Material nicht möglich, da die Angaben in den Journalen, soweit es sich um die feineren Unterschiede der Einstellung und des Standes des Kopfes handelte, vielfach nicht genau genug waren. --

Je enger also das Becken, je geringer die Anzahl der vorangegangenen Entbindungen der Patientin, je ungünstiger der Stand des Kopfes ist, desto entschiedener muss man sich an die Forderung halten, nur auf stricte, von der Mutter ausgehende Indication zur Entbindung hin einen Versuch mit der hohen Zange zu machen. --

Wir kommen also zu dem Resultate, dass die hohe Zange ein berechtigter und, wenn auch nicht immer, so doch oft vom besten Erfolg gekrönter Eingriff besonders in jenen Fällen 
von engem Besken ist, die durch folgende Momente charakterisirt werden:

Mehrgebärende. - Conjugata vera über $7 \frac{1}{2} \mathrm{~cm}$. - Für die Zangenextraction genügende Erweiterung des Muttermundes. Kopf in günstiger Einstellung, ganz oder annähernd mit seinem grössten Durchmesser im Beckeneingang. - Indication zur Entbindung von Seiten der Mutter (besonders bei beginnenden Ausziehungserscheinungen des unteren Uterinsegmentes und Quetschungserscheinungen).

Diese Indicationsstellung deckt sich ungefähr mit derjenigen, für die Gusserow ${ }^{1}$ ) den Versuch mit der Achsenzugzange emplabl.

Trotz aller Einschränkungen, die nach alledem im Gebrauch der hohen Zange nothwendig erscheinen, kann ich es also nicht für berechtigt halten, wenn Menge ${ }^{2}$ ) die hohe Zange beim engen Becken vollständig verwirft, und jeh muss, jedenfalls für die Becken mit einer Conjugata vera von über $7 \% \mathrm{~cm}$, Krönig ${ }^{3}$ ) entschieden widersprechen, der den hohen Forceps für eine Operation erklärt, die nicht im Stande wäre, die Prognose für Matter und Kind bei engem Becken günstiger zu gestalten. -

\section{Geburten, bei denen die Kraniotomie ausgeführt wurde,}

Die Perforation des vorangehenden Kopfes wurde bei engem Becken 51 Mal ausgeführt, einschliesslich der 13 bereits im Vorhergehenden mitberücksichtigten Fälle, in denen der Perforation ein vergeblicher Versuch mit der bohen Zange vorausging. Im Anschluss an die Perforation wurde die Geburt stets durch die Extraction mit dem Kranioklasten beendigt.

Im Allgemeinen kam der Braun'sche Kranioklast zur Verwendung. In der letzten Zeit habe ich einige Male auch den Febling'schen viertheiligen Kranioklasten ${ }^{4}$ ) benutzt und mich in einem. besonders schwierigen Falle von dem Vortheil, den das Instrument vor dem Braun'schen darzubieten vermag, überzeugen können. - Die Ausführung der Operation schien mir be-

1) Gusserow, Centralblatt f. Gynäk. 1892. No. 17.

2) Menge, Centralblatt f. Gynäk. 1901. S. 681.

3) Krönig, Münchener med. Wochenschr. 1902. No. 32.

4) Fehling, Ein viertheiliger Kravioliast (Kephalothrypt-belktor). Centralblatt f. Gynäk. 1898. 
278 W alff, Weiterer Beitrag zur Therapie der Geburt beim engen Becken.

sonders dadurch erleichtert zu sein, dass der Fehling'sche Kranioklast eine Beckenkrümmung besitzt.

Fall Kornetzky (Journ.-No. 92, Jabrg. 1901/02): Rachitisch plattes Becken: Spinae 28, Cristae 281/2, Trochanteren 31, Conjug. ext. 161/2, Conjug. diagon. $91 / 2 \mathrm{~cm}$. 41 jährige XII para (alle früheren Entbindungen wurden operativ durch die geburtshülff. Poliklinik der Königl. Charité beendet): 2. Schädellage mit Nabelschnurvorfall. Kind todt. Ausziehung des unteren Uterinsegmentes. Nach vielen vergeblichen Versuchen, die zunächst von anderer Seite, alsdann auch von mir gemacht waren, den Kopf mit dem Braun'schen Kranioklasten, der immer wieder ausriss, zu extrahiren, gelang es mir schliesslich erst dann und zwar verbältnissmässig leicht, die Operation zu vollenden, als ich den Fehlingschen Kranioklasten angelegt hatte. Das mittlere Blatt kam in die Perforationsöffuung, das rechte und linke über Gesicht und Hinterhaupt. Der Kranioklast wirkte auf diese Weise zugleich als Kephalothryptor. $51 \mathrm{~cm}$ langes Kind.

Im Einzelnen ist hinsichtlich der 51 Kraniotomien zu bemerken:

Die Perforation wurde ausgeführt:

a) Bei 1. bezw. 4. Schädellage: $10 \mathrm{Mal}$

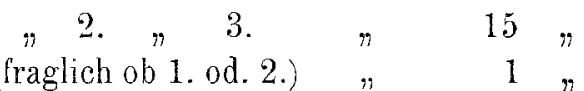

b) Bei Hinterscheitelbeineinstellung: $5 \mathrm{Mal}$

7

7

2. Gesichtslage: 3 n

1. oder 2. Stirnlage: $7 n$ (davon 5 Mal

bei 2. Stirnlage, 1 Mal 1. Stirnlage, $1 \mathrm{Mal}$ fraglich ob 1. oder 2. Stirnlage).

"Schädellage mit Armvorfall: . . . . . 2 Mal

c) Bei Schädellage mit Nabelschnurvorfall: . . . . . 6 ,

$n$ Arm- und Nabelschnurvorfall: . 1 n

"Hinterscheitelbeineinstellung mit Nabelschnurvorfall: 1 ",

ad a) Betrachten wir zunächst die 26 Fälle, in denen es sich um gew öhnliche Schädellagen ohne weitere Complication handelte:

In 10 von diesen 26 Beobachtungen ging der Perforation ein vergeblicher Versuch mit der hohen Zange vorauf; in 2 Fällen wurde zunächst ein vergeblicher Wendungsversuch gemacht. Die vergebliche Anlegung der Zange war 9 mal durch die Poliklinik, einmal, ehe poliklinische Hülfe eintraf, durch einen Privatarzt ausgeführt worden. -

In 9 Fällen wurde vor der Perforation der Tod des Kindes constatirt. In einer zehnten Beobachtung waren die kindlichen Herztöne "nicht mehr deutlich " zu hören. 
Wolff, Weiterer Beitrag zur Therapie der Geburt beim engen Becken.

In 13 Fällen waren vor den Operationen (vor dem Zangenversuch oder der sofort vorgenommenen Perforation) schon mehr oder weniger hochgradige Störungen im Befinden des Kindes festzustellen.

In 3 Fällen, [bei denen zur Perforation geschritten wurde, nachdem anderweitige Entbindungsverfahren (Zangen- bezw. Wendungsversuch) keinen Erfolg gehabt hatten] waren vor den operativen Eingriffen Störungen im Befinden des Kindes nicht constatirt worden.

Die Indication zu den operativen Maassnahmen (zur sofortigen Perforation oder zunächst zu anderen, vergeblich versuchten Eingriffen) wurde abgegeben durch:

Ausziehung des unteren Uterinsegments (drohende Uterusruptur): 13 mal.

Spontane Uterusruptur: 3 mal (stets sofortige Perforation obne andere Entbindungsversuche).

Fieber während der Geburt: $9 \mathrm{mal}$.

Wehenschwäche und hochgradige Erschöpfung der Mutter: 1 mal (Perforation nach vergeblichem Zangenversuch). -

ad b) Ein anderes Bild geben die Fälle, in denen es sich um Gesichts- oder Stirnlagen, Hinterscheitelbeineinstellung oder Schädellage mit Armvorfall handelte:

Bei diesen 17 Fällen wurde vor der Kraniotomie nur $3 \mathrm{mal}$ ein vergeblicher Versuch mit der hohen Zange, dagegen 4 mal ein vergeblicher Wendungsversuch gemacht.

Nur in 3 Fällen waren die Herztöne des Kindes vor der Perforation nicht mehr festzustellen.

In 11 Fällen waren die Herztöne der Frucht vor Beginn der Operation schon mehr oder weniger stark beschleunigt, verlangsamt oder unregelmässig.

In 3 Beobachtungen, unter denen 2 mal zuerst die Wendung, einmal die Zange vergeblich versucht wurde, waren vor Beginn der Operationen Störungen im Befinden des Kindes nicht constatirt. -

Die Indication zu den operativen Eingriffen wurde hier abgegeben durch:

Ausziehung des unteren Uterinsegmentes (drohende Uterusruptur): $11 \mathrm{mal}$.

Spontane Uterusruptur: $1 \mathrm{mal}$ (sofortige Perforation, vorher keine anderen Entbindungsversuche).

Fieber während der Geburt: 3 mal. 
280 Wolff, Weiterer Beitrag zur Therapie der Geburt beim engen Becken.

Vergeblichen Wendungsversuch bei Hinterscheitelbeineinstellung: 2 mal. -

ad c) In den 8 Fällen schliesslich, in denen es sich um Perforationen bei Nabelschnurvorfall handelte, war das Kind stets mit Sicherheit vor der Perforation abgestorben. -

Im Ganzen wurde also unter den 38 Fällen, in denen die Kraniotomie ausgeführt wurde, zur Perforation oder zunächst zu anderen vergeblichen Entbindungsversuchen geschritten:

1. Nachdem das Kind sicher oder mit grösster Wahrscheinlichkeit todt war: In 21 Fällen.

2. Bei noch lebendem, aber in seinem Befinden nachweislich bereits geschädigtem Kinde: In 24 Fällen.

3. Ehe Störungen im Befinden des Kindes festzustellen waren: In 6 Fällen. -

Das am stärksten verengte Becken, bei dem die Perforation des vorangehenden Kopfes ausgeführt wurde, hatte eine Conjugata vera von etwa $6 \mathrm{~cm}$. Es handelte sich um die folgende Beobachtung:

Fall Eggloff (Journ.-No. 525, Jahrg. 1900/01): Rachitisch plattes Becken: Spinae 27, Cristae $281 / 2$, Conjugata exterma 17, Conjugata diagonalis $8 \mathrm{~cm}$.

26 jährige I para. 20. November $1 / 210 \mathrm{Uhr}$ Abends: Blasensprung. Um 12 Uhr Nachts wird poliklinische Hülfe nachgesucht. 3. Schädellage. Muttermund fünfmarkstückgross. Kopf mit einem kleinen Segment im Beckeneingang. Promontorium mit geradem Finger leicht $\mathrm{zu}$ erreichen. Temperatur $38,2^{\circ}$, Puls 88 . Kindliche Herztöne 162, Abgang von Meconium.

Mit Rücksicht auf das bei der Mutter bereits eingetretene Fieber und die im Befinden des Kindes bereits festzustellenden Störungen erscheint es dringend erwünscht, die Geburt, wenn irgend möglich, per vias naturales zu beenden.

Es wird abwartend verfahren.

21. November 4 Ubr Nachmittags: Temperatur 38,7 ${ }^{0}$, Puls 108. Unteres Uterinsegment auf Druck schmerzhaft. Contractionsring 5 Querfinger breit über der Symphyse. Kindliche Herztöne 120-160. Reichlicher Abgang von Meconium. Der Kopf steht ziemlich unverändert im Beckeneingang. - Nunmehr wird die Perforation mit dem trepanförmigen Perforatorium vorgenommen. Die Extraction des Kopfes mit dem Kranioklasten war ausserordentlich schwierig. Nach etwa $1 \frac{1}{2}$ stündigen Bemühungen gelingt es, den Kopf mittelst des Braun'schen Kranioklasten durch das Becken zu ziehen.

Der Damm blieb unverletzt. $56 \mathrm{~cm}$ langer Knabe. Wochenbett normal.

Was nun den Ausgang der 51 Entbindungen, in denen die 
Kraniotomie stattfand, für die Mütter anbetrifft, so trat 3 mal der Exitus letalis ein.

Von diesen 3 Frauen starb eine an Sepsis 4 Wochen post partum. In dieser Beobachtung war bereits während der Entbindung hohes Fieber (Temperatur 39,7 ${ }^{\circ}$, Puls 120) eingetreten, und dieser Umstand hatte (nach dem Tode des Kindes) die Indication zur Perforation und zu einer bei noch engem Muttermund sehr schwierigen Extraction mit dem Kranioklasten abgegeben ${ }^{1)}$.

Die beiden anderen Patientinnen starben in Folge einer vor der Kraniotomie spontan eingetretenen Uterusruptur:

1. Fall Mersetzki (Polikl. Journ.-No. 78, Jahrg. 1892/93): Allgemein verengtes Becken. Spinae 25, Cristae 28, Trochanter. 32, Conj. externa $20^{1 / 2}$, Conj. diag. $10^{1 / 2}-10 \mathrm{~cm}$.

30 jährige II para (bei der ersten Entbindung Wendung, Perforation des nachfolgenden Kopfes): 1. Schädellage. Der die Entbindung beobachtende Praktikant meldet, nachdem die Temperatur auf $39^{\circ}$, der Puls auf 120 gestiegen war.

Der Assistenzarzt findet die Frau moribund, den Uterus rechts rupturirt, Kopf abgewicben, Nabelschnur pulslos vorgefallen. Kraniotomie. Grosser Knabe. Die Frau stirbt noch während der Entbindung. Die Placenta wird manuell aus dem Abdomen entfernt.

2. Fall Pilarzyk (Journ.-No. 746, Jahrg. 1895/96): Plattes Beckelı. Conj. diagon. $11 \frac{1}{2} \mathrm{~cm}$.

35 jährige Ill para. (Frühere Entbindungen normal.) Der zur Entbindung gerufene Assistenzarzt findet die Frau fast in extremis. Puls 152. Kindliche Herztöne waren schon vor Ankunft des Arztes nicht mit Sicherheit feststellbar. Die spontan eingetretene Uterusruptur wird sofort diagnosticirt. Stirnlage. Perforation und sehr schwierige Extraction mit dem Kranioklasten. $3600 \mathrm{~g}$ schwerer Knabe. Starke Blu tung. Da ein Transport in die Klinik bei dem Zustande der Patientin nicht mehr möglich war, wird an Ort und Stelle die Laparotomie und Amputation des Uterus ausgeführt. Patientin stirbt während der Naht der Bauchdecken.

Nach den übrigen Geburten war das Wochenbett 7 mal fieberhaft. $6 \mathrm{mal}$ wurde Genesung beobachtet; die 7. Patientin, die an einer Venenthrombose erkrankt war, wurde gebessert in Privatbehandlung entlassen. -

Incisionen in den Muttermund wurden 2 mal, Dammincision wurde 1 mal ausgeführt. 2 mal kam bei Erstgebärenden ein Dammriss 1. Grades vor. -

Als wichtigstes Ergebniss dieser 51 Beobachtungen,

1) Fall Grenz, Journ.-No. 181, Jahrg. 1900/01. 
in denen bei engem Becken die Perforation und Extraction mit dem Kranioklasten ausgeführt wurde, ist hervorzuheben:

Trotz der häufig grossen Schwierigkeiten der Entbindung und trotz vielfacher vorangegangener vergeblicher Versuche, die Geburt im Interesse des Kindes durch die Zange oder die Wendung zu beenden, ist in keinem Falle ein Exitus letalis oder eine schwere Verletzung der Mutter auf die Perforation oder Kranioklasie zurückzuführen gewesen.

Von den 3 Todesfällen war bei der durch Sepsis gestorbenen Frat die Infection nachweislich schon vor Beginn der Perforation, bei den beiden durch Uterusruptur gestorbenen die spontane Gebärmutterzerreissung ebenfalls vor der Perforation eingetreten.

Man kann diese Todeställe selbstverständlich nicht der Kraniotomie zur Last legen.

Wir dürfen daher die Prognose der Kraniotomie an sich, trotz der oft sehr langen Dauer der Operationen, zweckmässige Ausführung des Eingriffes vorausgesetzt, für durchaus gut ansehen und sagen, dass unter denjenigen Fällen, die durch irgend eine entbindende Operation überbaupt noch zu retten sind, die Mortalität der Kraniotomie gleich Null ist.

Da es sich in allen drei Beobachtungen, in denen die llutter starb, um die Perforation eines bereits abgestorbenen oder moribunden Kindes handelte, war also unter den 30 Fällen, in denen das noch lebensfähige Kind perforirt wurde, - unter allen denjenigen Beobachtungen also, wo die Frage überhaupt hätte erwogen werden können, ob man im Interesse des Kindes an Stelle der Kraniotomie eine andere Operation ausführen sollte, - die Mortalität, ohne jede Einschränkung, gleich Null.

Das Resultat war unter poliklinischen Verhältnissen unseren Erfahrungen nach ebenso gut, wie es heutzutage, der allerdings auf eine viel grössere Anzahl von Kraniotomien gestützten Arbeit von Bretsehneider ${ }^{1}$ ) zufolge, in der Klinik ist:

Nach Bretschneider kamen in der Leipziger Klinik unter 132 Fällen von Perforation und Extraction mit dem Zweifel'schen

1) Bretschneider, Ueber 132 Fälle von Perforation und Extraction mit dem Zweifel'schen Kranio-Kephaloklast. Dieses Archiv. Bd. 63. 1901. 
Kranio-Kephaloklasten 10 Todesfälle vor, von denen aber keiner dem Kranio-Kephaloklasten zur Last gelegt werden konnte. -

Die Thatsache, dass die Prognose der Kraniotomie heutzutage unter aseptischen Maassnabmen, selbst bei den ungünstigen äusseren Verhältnissen der Poliklinik, eine so unbedingt gute ist, ist von grossem Interesse:

Es fällt unter diesen Umständen ein Vergleich, zwischen Kraniotomie und Kaiserschnitt') auch heute, trotz der wesentlichen Verbesserung; die die Prognose der Sectio caesarea erfahren hat, in erheblichem Maasse zu Gunsten der Kraniotomie aus.

Hierauf muss ganz besonders Denjenigen gegenüber hingewiesen werden, die durch einen Vergleich der Resultate der Kraniotomie und des Kaiserschnitts zu beweisen suchen, dass die Zeit gekommen sei, dio Perforation des lebenden Kindes unter allen Umständen durch die Sectio caesarea zu ersetzen. [Koss$\operatorname{mann}{ }^{2}$.]

Solchen Schlussfolgerungen gegenüber ist aber nicht nur auf den Unterschied in den Mortalitätsstatistiken der beiden Operationen hinzuweisen; viel wichtiger als die blossen Zahlen sind folgende Erwägungen:

In den Fällen, in denen in der geburtshilflichen Poliklinik der Charité die Kraniotomie vorgenommen wurde, lagen die Verbältnisse ganz anders als in jenen, auf die sich die Resultate günstig ausgefallener Kaiserschnittsstatistiken überhaupt beziehen:

Wie bereits im Vorhergehenden erwähnt, wurden wir in der grossen Mehrzahl der Fälle erst nach dem Blasensprung gerufen und gewöhnlich hatten bereits vor Anwesenheit des Arztes innere Untersuchungen stattgefunden.

Die Ueberführung der Kreissenden in die Klinik, wie es für die Sectio caesarea, wenn auch nicht unbedingt nothwendig, so doch jedenfalls wünschenswerth ist, wäre häufig nicht ausführbar gewesen. -

Veit $^{3}$ ) giebt dic Vorsichtsmaassregeln an, die den Kaiser-

1) Kossmann (Das Recht des Arztes und der Mutter über Leben und Tod des neugeborenen Kindes. Die Heilkunde. 1902. Januar) giebt die Mortalität der Mütter beim Kaiserschnittauf 10 pCt. an.

2) Kossmann, I. c. u. "Indication und Recht zur Tödtung des Fötus", Vortrag in der Berliner medicin. Gesellschaft am 22. Januar 1902. (Referat: Deutsche med. Wochenschr. 1902. Vereinsbeilage No. 5.)

3) Veit, Beiträge zur Geburtsh. und Gynäk. Bd. 4. 1901. S. 325. 
Wolff, Weiterer Beitrag zur Therapie der Geburt beim engen Becken.

schnitt zu einer lebenssicheren Operation machen, und die er daher bei der Stellung der relativen Indication für geboten erachtet:

"Vor Allem", sagt er, "nehme ich die Schwangeren 3 Wochen ror dem erwarteten Endtermin in die Klinik auf und unterlasse jede weitere Untersuchung; auch warne ich die Schwangere vor allen Berührungen ihrer Genitalien. Demnächst verzichte ich auch bei Beginn der Geburt auf die vaginale Untersuchung; vielmehr beginne ich die Operation, sobald die Frau angiebt, Wehen $z u$ haben und sobald ich deutliche Contractionen in kurzen Pausen feststelle".

Mit diesen Cautelon vergleiche man die Umstände, die sich, bedauerlicher Weise zwar, aber doch eben thatsächlich, heutzutage noch oft genug in der Praxis darbieten, und mit denen zu rechnen man daher verpflichtet ist. -

In seiner Abhandlung, in der er die Kraniotomie des lebenden Kindes vollständjg verwirft, erörtert nun Kossmann 1 ) die tech$n$ ischen Vorsichtsmaassregeln, die er bei der Ausführung einer Sectio caesarea unter ungünstigen äusseren Verhältnissen für nothwendig erachtet und spricht sich alsdann folgendermaassen aus: "Wer", sagt er, "die hier wiedergegebenen wenigen, aber entscheidenden Vorsichtsmaassregeln beobachtet, sich auch aller überflüssigen Umständlichkeiten, die nur zur Verwirrung und zu Missgriffen führen, enthält, der wird, wo nicht schon aus anderen Gründen eine Gefährdung der Kreissenden eingetreten ist, durch den Kaiserschnitt an sich kaum jemals eine Patientin verlieren, wohl aber sich des Bewusstseins erfreuen können, so manches Kind am Jeben erhalten zu haben".

Im Hinblick auf diese Ausführungen Kossmann's, die sich an den Praktiker richten, kann aber nicht energisch genug betont werden, dass eben eine "Gefährdung der Mutter", die die Prognose des Kaiserschnitts ungünstiger gestaltet, ausserordentlich häufig bereits vorhanden ist, wenn der Arzt zu der Kreissenden kommt. - Schon der Blasensprung ist als ein ungünstiges Moment anzusehen. Eine nicht unerhebliche Gefährdung aber ist zweifellos dann anzunehmen, wenn innere Untersuchungen, noch dazu ohne ärztliche Controlle, stattgefunden haben. -

1) Kossmann, Die Heilkunde. 1902. Januar. 
Der Arzt darf nicht erst dann, wenn ein Kaiserschnitt ihm unglücklich verlaufen ist, zu untersuchen beginnen, ob irgend ein schon vor der Operation eingetretener Umstand die Schuld an diesem Ereigniss trägt. Vielmehr muss der Geburtshelfer, ehe er aus relativer Indication eine Sectio caesarea vornimmt, so wejt wie möglich, zu ermitteln' suchen, ob die Verhältnisse des Falles noch derartige sind, dass man $z u$ dieser Operation rathen darf ${ }^{1}$ ). -

Wenn jemand hätte wagen wollen, principiell in den 30 Fällen, in denen in der Poliklinik der Charité das lebende Kind perforirt wurde, den Kaiserschnitt auszuführen, so würde die Mortalität der Mütter bei diesem Vorgehen zweifellos eine ausserordentlich hohe gewesen sein, während sie bei der Kraniotomie in diesen 30 Beobachtungen der Jahre 1892-1902 Null war. -

Sicherlich wäre auch von den Kindern eine beträchtliche Anzahl, in den vorgeschrittenen Stadien der Geburt, um die es sich hier handelte, durch die Sectio caesarea nicht mehr zu retten gewesen; denn nur in 6 Fällen wurde zur Vornahme der Entbindung zu einer Zeit geschritten, wo das Befinden des Kindes noch gänzlich ungestört, dasselbe also noch in vollem Maasse lebenskräftig war $^{2}$ ). -

Aus diesen Gründen meine ich, dass ein Vergleich zwischen den heuzutage vorliegenden Statistiken der Kraniotomie und der Sectio caesarea, bei der Verschiedenheit der Umstände, unter denen man sich zu der einen oder der anderen Operation $\mathrm{zu}$ entschliessen pflegte, selbst dann nicht ohne Weiteres die ausgedehntere Empfehlung des Kaisersehnittes aus relativer Indication erlauben würde, wenn die in den letzten Jahren bei beiden Operationen für die Mütter erzielten Resultate annähernd die gleichen wärèn. --

1) Anm.bei der Correctur: Nach Ablieferung des Manuskriptes dieser Arbeit erschien die wichtige Abhandlung von $\mathrm{H}$ ofmeier ,über die Berechtigung der Perforation des lebenden Kindes" (Zeitschr. f. Geburtşh. u. Gynäli. Bd.48. 1903) in der Hofme ier Pinard gegenüber betont, dass die, Perforation des lebenden Kindes in der allgemeinen Praxis gelegentlich gar nicht zu umgehen sei." - "Als Arzt", sagt Hofmeier, "hat der Geburtshelfer eben die Gesammtheit der Situation in Erwägung za ziehen und zu beurtheilen und nicht nur die Aufgabe zu lösen, unter allen Umständen ein noch athmendes Kind an's Licht zu befördern."

2) Vergl. v. Franqué, Die Entstehung und Behandlung der Uterusruptur. Würzburger Abhandl. 1901. II. Bd. Heft I. S. 21. 
Etwas ganz anderes ist es natürlich, wenn es sich um die Ausfübrung des Kaiserschnitts aus relativer Indication unter wirklich günstigen Bedingungen handelt, also da, wo man dje Frau frühzeitig, womöglich, wie Veit wünscht, noch vor Beginn der Geburtswehen zu sehen bekommt.

Hicr wird man mit Rücksicht auf die hentzutage viel günstigeren Ergebnisse dieser Operation allerdings viel energiseher als früher für die Sectio caesarea einzutreten haben.

Da sich aber diese günstigen Verhältnisse erfahrungsgemäss in der allgemeinen Praxis verhältnissmässig selten darbieten, so ist die Kraniotomie ein Fingriff, der selbstverständlich nur auf strengste Indication hin bei noch lebendem Kinde ausgeführt werden darf, der heute seltener als früher nothwendig ist, and hoffentlich in $\mathrm{Zukunft}$ immer mehr vermieden werden kann, der aber zur Zeit doch nicht weniger als früher berechtigt ist und $z u$ dessen Ausführung der Geburtshelfer vielfach verpflichtet bleibt.

Er würde ohne denselben so und so oft, statt wenigstens ein Menschenleben sicher zu retten, mit grösster Wahrscheinlichkeit zwei opfern. ${ }^{1}$ )

Es sind auch heute noch die Ausführungen Wyder's ${ }^{2}$ ), der im Jahre 1888 dio Mortalität der Sectio caesarea auf 17,9 pCt., die der Kraniotomie bei engem Becken auf $8,4 \mathrm{pCt}$. angab, in vieler Beziehung beherzigenswerth. Wyder kam damals zu dem Schluss, dass selbst dann, wenn die Zeit gekommen wäre, wo die Mortalität beim Kaiserschnitt und bei der Kraniotomie gleich gross sei, und wo man in Kliniken in vollstem Maasse die Sectio caesarea an Stelle der Perforation lebender Kinder setzen müsse, doch $n$ in der Privatpraxis" "nach wie vor die Kraniotomie eine grosse Rolle spielen" werde. -

Im Anschluss an den obigen Bericht über die bei engem Becken ausgeführten Kraniotomien ist noch auf folgende Einzelheiten hinzuweisen:

Von besonderem Interesse ist, dass bei einer Erstgebärenden mit einer Conjugata vera von etwa $6 \mathrm{~cm}$ trotz kräftiger Ent-

1) Vergl. meine Bemerkungen in der Discussion zu Kossmann's Vortrag. -- Berl. Klin. Wochenschr. 1902. No. 8.

2) Wyder, Perforation, künstliche Frühgeburt und Sectio caesarea in ihrer Stellung zur 'Therapie beim engen Becken. Dieses Archiv. Bd. 32.1888. Vergl. auch Leopold, Arbeiten aus der Kgl. Frauenklinik in Dresden. Bd. I. 189?. S. 388 . 
Wolff, Weiterer Beitrag zur Therapie der Geburt beim engen Becken. 287

wickelung des Kindes die Extraction mit dem Kranioklasten ohne Schaden für die Mutter gelang. Hierbei handelte es sich also um einen Grad der Beckenverengung, bei dem man im Allgemeinen bereits eine absolute Indication zum Kaiserschnitt annimmt.-

Der Vergleich zwischen den Geburten mit gewöhnlicher Schädellage" und denen mit abnormer Einstellung des Kopfes (Gesichtslage etc.) zeigte Folgendes:

Bei der ersten Reihe von Fällen wurde absolut und relativ viel häufiger als bei der zweiten der Tod des Kindes vor der Perforation festgestellt. Hieraus ergiebt sich, dass die Nothwendigkeit zu perforiren bei gewöhnlichen Schädellagen im Allgemeinen erst in einem späteren Stadium der Geburt, als bei den abnormen Einstellungen eintritt. - .

\section{Abschnitt II. \\ Die mit vorangehendem Kopfe verlaufenen Geburten, je nach der Anzahl der vorangegangenen Geburten.}

Unter 297 Geburten, die mit vorangehendem Kopfe beendet wurden, betrafen:

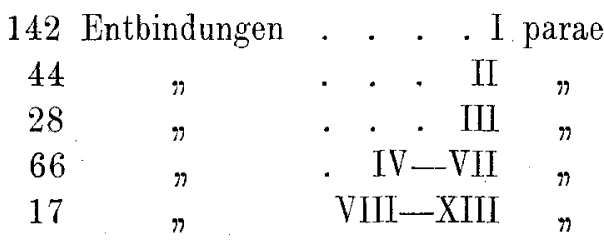

Wir betrachten nun den Verlauf dieser Geburten bei den I-, II- u. s. w. paris zunächst mit Rücksicht darauf, in welcher Anzahl dieselben spontan, durch die gewöhnliche Zange, durch die hohe Zange oder durch die Kraniotomie beendet wurden. $\left.{ }^{1}\right)$ -

Bei der Betrachtung der folgenden Tabellen ist ein Moment stets im Auge zu behalten:

Wie bereits oben erwähnt, ist unter unserem poliklinischen Material die Anzahl der spontan verlaufenen Geburten lediglich aus dem äusserlichen Grunde eine sehr geringe, weil wir

1) Zu den bohen Zangen sind im folgenden (anders als im vorhergehenden Abschnitte) die vergeblichen Zangenversuche nicht gezählt; vielmehr sind diese Fälle, je nach ihrem schliesslichen Ausgange, lediglich zu den spontanen Geburten bezw. den Kraniotomien gerechnet. 
288 Wolff, Weiterer Beitrag zur Therapie der Geburt beim engen Becken.

gewöhnlich erst zur Entbindung gerufen werden, wenn sich bereits Störungen im Verlaufe der Geburt za zeigen begonnen haben.

Der Vollständigkeit halber' gebe ich die Anzahl der spontan verlaufenen Entbindungen im folgenden zwar ebenfalls an, ein Wert ist aber, soweit es sich nicht lediglich um die Verbältnisse in der Poliklinik, sondern um einen Rückschluss auf allgemeine Verhältnisse handelt, nur auf den Vergleich der Zahlen, die für die operativ beendeten Geburten gefunden sind, zu legen:

Tabelle 1 .

\begin{tabular}{|c|c|c|c|c|c|c|c|c|}
\hline \multirow[t]{2}{*}{ Unter: } & \multicolumn{2}{|c|}{$\begin{array}{l}\text { Spontan ver- } \\
\text { lauf. Geburten }\end{array}$} & \multicolumn{2}{|c|}{$\begin{array}{c}\text { Gewöhnliche } \\
\text { Zangen }\end{array}$} & \multicolumn{2}{|c|}{$\begin{array}{l}\text { Hohe } \\
\text { Zangen }\end{array}$} & \multicolumn{2}{|c|}{ Kraniotomien } \\
\hline & Anzahl & pCt. & Anzahl & pCt. & Anzahl & pCt. & Arrzahl & pCt. \\
\hline I-paris & 42 & 29,6 & 68 & 47,9 & 10 & 7,0 & 22 & 15,5 \\
\hline II-, & 17 & 38,6 & 10 & 22,7 & 7 & 15,9 & 10 & 22,7 \\
\hline III- " & 9 & 32,1 & 5 & 17,9 & 9 & 32,1 & $\bar{\partial}$ & 17,9 \\
\hline 66 IV-VII- , & 24 & 36,4 & 7 & 10,6 & 24 & 36,4 & 11 & 16,7 \\
\hline 17 VIII-XIIl- " & 7 & 41,2 & 0 & 0,0 & 7 & 41,2 & 3 & 17,6 \\
\hline
\end{tabular}

Ein interessantes Resultat liefern in dieser Tabelle die Z angenoperationen:

Es zeigte sich, dass die Anzahl der Fälle, in denen der Forceps an den tiefstehenden Kopf angelegt werden musste, von Geburt zu Geburt stetig und zwar sehr erheblich, nämlich von 47,9 pCt. bei I paris auf 0 pCt. bei VIII-XIII paris, fällt.

Gerade umgekebrt steigt von Geburt zu Geburt stetig und sehr bedeutend der Procentsatz der bei hochstehendem Kopfe ausgeführten Zangenoperationen (von 7,0 pCt. bei I paris auf 41,2 pCt. bei VIII-XIII paris).

Hat der Kopf also einmal den verengten Beckeneingang ganz übersehritten, so ist es mit jeder folgenden Geburt immer seltener notwendig, die Geburt noch durch die Zange zu beenden.

Andererseits aber treten unter den mit vorangehendem Kopfe verlaufenen Entbindungen von Geburt zu Geburt immer häufiger bereits so frühzeitig Geburtsstörungen auf, dass die Zange schon bei noch hochstehendem Kopfe angelegt werden muss. -

Was die Kraniotomien anbetrifft, so kommen diese bei Mehrgebärenden in grösserer Anzahl als bei Erstgebärenden vor. Die einzelnen Gruppen der Mehrgebärenden liessen keine erheblichen Unterschiede erkennen. -- 
Es ist von Interesse, mit den abigen Zahlenverhältnissen diejenigen zu vergleichen, die sich ergeben, wenn man die Häufigkeit der verschiedenen Entbindungsarten bei I-, II- u. s. w. paris nicht, wie hier geschehen, unter den mit vorangehendem Kopfe verlaufenen, sondern unter der Gesammtzahl der Entbindungen bei engem Becken (also einschliesslich aller feblerhaften Lagen, Wendungen etc.) berechnet. Die Abweichungen, die sich hinsichtlich der Häufig-keit der einzelnen Operationen in diesen beiden Statistiken herausstellen, sind hauptsächlich dadurch bedingt, dass bei Mehrgebärenden die Wendungen so ausserordentlich an Zahl überwiegen:

Nach den übereinstimmenden Angaben von Michaelis ${ }^{1}$ ), Weidling. ${ }^{2}$, Winter ${ }^{3}$ ) und Ahlfeld4) wird unter der Gesammtzahl der Eatbindungen bei engem Becken der Procentsatz der spontan verla ${ }^{2}$ fenen von Geburt zu Geburt geringer. -

Die Zangenoperationen nehmen nach Michaelis bei den späteren Entbindungen ebenfalls ab.

Weidling stellte hinsichtlich der Zangenoperationen zwar auch fest, dass die Zange am häufigsten bei der ersten, seltener bei der zweiten und dritten Geburt zur Anwendung kam; abweichend von Nichaelis aber fand er, dass sie von der vierten Entbindung an wieder häufiger gebraucht wurde.

Win ter ermittelte, dass , die zum Gelingen des hohen Forceps günstige Kopfeinstellung" "von 11 pCt. bei Erstgebärenden auf 8 pCt. bei Nehrgebärenden abnimmt." -

Was das Material der geburtshülflichen Poliklinik der Charité anbetrifft, so vertheilten sich die sämmtlichen $581 \mathrm{Ge}-$ burten bei engem Becken folgendermaassen:

\begin{tabular}{|c|c|c|c|c|c|c|c|c|c|c|c|c|c|c|}
\hline \multirow[t]{2}{*}{ Lnter: } & \multicolumn{2}{|c|}{$\begin{array}{c}\text { Spont. } \\
\text { Verlauf in } \\
\text { Kopflage. }\end{array}$} & \multicolumn{2}{|c|}{$\begin{array}{c}\text { Gewöhnl. } \\
\text { Zangen }\end{array}$} & \multicolumn{2}{|c|}{$\begin{array}{c}\text { Hohe } \\
\text { Zangen }\end{array}$} & \multicolumn{2}{|c|}{$\begin{array}{c}\text { Kranio- } \\
\text { tomien }\end{array}$} & \multicolumn{2}{|c|}{$\begin{array}{c}\text { Wendun- } \\
\text { gen }\end{array}$} & \multicolumn{2}{|c|}{$\begin{array}{l}\text { Becken- } \\
\text { endlagen }\end{array}$} & \multicolumn{2}{|c|}{$\begin{array}{c}\text { Embryo- } \\
\text { tomien }\end{array}$} \\
\hline & Anz. & pCt. & Anz. & pCt. & Anz. & pCt. & Anz. & pCt. & Anz. & pCt. & Anz. & pCt. & Anz. & pCt. \\
\hline I-paris & 42 & 22,7 & 68 & 36,8 & 10 & 5,4 & 22 & 11,9 & 26 & 14,1 & 16 & 8,6 & 1 & 0,5 \\
\hline 'II- ${ }^{-}$ & 17 & 16,8 & 10 & 9,9 & 7 & 6,9 & 10 & 9,9 & 47 & 46,5 & 10 & 9,9 & 0 & - \\
\hline IIII- & 9 & 11,4 & 5 & 6,3 & 9 & 11,4 & 5 & 6,3 & 45 & 57,0 & 6 & 7,6 & 0 & - \\
\hline 172 IV-VII- " & 24 & 14,0 & 7 & 4,1 & 24 & 14,0 & 11 & 6,4 & 89 & 51,7 & 17 & 9,9 & 0 & - \\
\hline 44 VIII-XIII-" " & 7 & 15,9 & 0 & 0,0 & 7 & 15,9 & 3 & 6,8 & 26 & 59,1 & 1 & 2,3 & 0 & - \\
\hline
\end{tabular}

Aus den vorstehenden Bemerkungen ist bereits zu entnehmen, dass die mit vorangehendem Kopfe verlaufenden Entbindungen bei engem Becken sich desto ungünstiger zu gestalten pflegen, je mehr Geburten vorangegangen sind. -

1) Michaelis, Das enge Becken. Leipzig. 1851.

2) Weiding, Die Prognose der Geburt bei engem Becken nach statistischen Ergebnissen der Hallenser Klinik und Poliklinik. Inaug.-Dissert. Halle. 1882.

3) Winter, l. c.

4) Ahlfeld, Lehrbuch der Geburtshülfe. Leipzig. 1898. 
Um hierron ein noch anschaulicheres Bild zu geben, fassen wir in der folgenden Tabelle die mit der hohen Zange und der Kraniotomie beendeten Geburten zusammen.

Die auf diese Weise gebildete Gruppe der "schwierig verLaufenen" Entbindungen enthält also sämmtliche Beobachtungen, in denen die Wehenkraft allein nicht ausreichte, den im Beckeneingang durch das enge Becken gesetzten Widerstand vollständig zu überwinden:

Tabelle II.

\begin{tabular}{ll|c|c}
\hline & & \multicolumn{2}{|c}{ Schwieriger Verlauf } \\
& Unter: & Anzahl & pCt. \\
& & & \\
& & & \\
142 & I-paris & 32 & 22,5 \\
44 & II- " & 17 & 38,6 \\
28 & III- " & 14 & 50,0 \\
66 & IV-VII- " & 35 & 53,0 \\
17 & VIII-XIII- $"$ & 10 & 58,8
\end{tabular}

Vergleicht man in dieser letzteren Tabelle die Häufigkeit des ${ }_{n}$ schwierigen Verlaufs" bei den I-, II- u. s. w. paris, so erhellt sehr deutlich, in welchem Maasse unter den bei engem Becken mit vorangehendem Kopfe verlaufenden Geburten mit jeder folgenden Entbindung die Schwierigkeiten anwachsen.

Damit sind wir zu einer sehr augenfälligen Bestätigung eines Resultates gelangt, auf das besonders Winter (l. e.) hingewiesen hat: Winter betonte, dass bei engem Becken ,bei Erstgebärenden die spontane Geburt oder wenigstens ein theilweises Ueberwinden des Beckeneingangs wahrscheinlich ist, während schon von der zweiten Geburt an die Aussichten auf ein Ein- oder Durchtreten des Kopfes immer ungünstiger werden " und zwar, wie er ausserdem herrorhebt, um so ungünstiger, nje schwerer und langdauernder die früheren Geburten waren."

Hinsichtlich der Erklärung dieser Thatsachen wird man sich Winter ohne weiteres anschliessen. Derselbe sieht die Gründe für diese Verschiedenheiten im Geburtsverlauf darin, dass bei Yehrgebärenden 1) der Kopf grösser und schwerer configurirbar als bei Erstgebärenden ist, 2) die Wehen schwächer sind, 3) immer schneller das Kind aus dem contractionsfähigen Uterus in den 
Wolff, Weiterer Beitrag zur Therapie der Geburt beim engen Beoken. 291

Durchtrittssohlauch austritt, 4) eine schwächere Action der Bauchpresse und ein Hängebauch zu bestehen pflegt. -

Es bleibt nun noch festzustellen, ob sich bei einer höheren Anzahl vorangegangener Geburten, entsprechend den grösseren Schwierigkeiten im Geburtsverlauf, auch eine höhere Mortalität zeigt:

Was hierbei zunächst die Mütter anbetrifft, so sei bemerkt, dass unter den 6 Frauen, die in Folge der Entbindung starben, der Exitus letalis eintrat:

Nach der 1. Geburt bei eịner Frau,

$\begin{array}{llllll}n & n & 2 . & n & n & \text { zwei Frauen, } \\ & n & 3 . & n & & \text { z wei Frauen, } \\ & n & 4 . & & & \end{array}$

Irgendwelchẹ Schlüsse lassen sich aus diesen kleinen Zahlen nicht ziehen. -

Hinsichtlich der Mortalität der Kinder ergiebt. sich die folgende Tabelle ${ }^{1}$ ):

Tabelle III.

\begin{tabular}{c|c|c|c}
\hline Unter: & $\begin{array}{c}\text { Anzahl } \\
\text { der Kinder } \\
\text { überhaupt }\end{array}$ & \multicolumn{2}{|c|}{ Todte_Kinder } \\
Anzahl & pCt. \\
\hline II-parae & 134 & 25 & 18,7 \\
III- " & 41 & 13 & 31,7 \\
IV-VII- " & 25 & 10 & 40,0 \\
VIII-XIII- " & 66 & 14 & 21,2 \\
& 14 & 1 & 7,1
\end{tabular}

Wie diese Zusammenstellung zeigt, stieg allerdings, in Uebereinstimmung damit, dass die Schwierigkeiten des Geburtsverlaufs immer mehr zunehmen, bis zur 3. Geburt der Procentsatz der todten Kinder bedeutend an; dagegen trat bei den späteren Entbindungen eine Verringerung der Mortalität der Kinder in so erheblichem Maasse ein, dass die Sterblichkeit bei den VIII-XIII paris nur noch $7,1 \mathrm{pCt}$. betrug und sogar viel geringer als bei Iparis war. -

Es ist dies eine zunächst auffallend erscheinende Thatsache.

1) Die 18 durch Nabelschnurvorfall gestorbenen Kinder und das eine schon vor Anlegung der Zange todte Kind sind unberücksichtigt gelassen. 
Wie im vorhergehenden aber erörtert worden ist, war die hohe Zange bei Frauen, die schon häufig geboren haben, - bei denen also nach dem obengesagten der Geburtsverlauf ein schwieriger $\%$ sein pflegt, - allerdings besonders oft nothwendig, sie ergab jedoch dabei gerade in diesen Fällen ein ganz besonders günstiges Resultat für die Kinder. -

In Bezug auf die zuletzt angeführte Tabelle III. muss ich aber noch besonders darauf hinweisen, dass diese nur zeigt, wie sich die Verhältnisse in der Poliklinik gestaltet haben, ohne dass daraus direct hervorgeht, wie die Mortalität der Kinder , im Allgemeinen" sein würde, (dies heisst, wie die Mortalität wäre, wenn man die Möglichkeit hätte, unter Anwendung der in der Poliklinik befolgten Behandlungsprincipien, alle in einem bestimmten Zeitraum an einem bestimmten Ort rorkommenden Entbindungen der Frauen mit engem Becken zu beobachten). -

Wenn aber auch die in Tabelle III angegebenen Mortalitätsziffern nicht mit dem Ergebniss übereinstimmen, das für die Sterblichkeit der Kinder bei engem Becken „im Allgemeinen" das Richtige wäre, so kann man auf Grund des poliklinischen Resultates hinsichtlich eines "allgemeingültigen " doch wenigstens folgendes sagen:

Es liegt, wie betont, im Character der Poliklinik, dass die spontan verlaufenden, also gerade die günstigen Entbindungen mit geringer Mortalität, in der Poliklinik verhältnissmässig selten zur Beobachtung gelangen. Daraus kann man zunäehst schliessen, dass die Mortalitätsziffern der Poliklinik sich ungünstiger gestalten müssen, als die einer allgemein gültigen Statistik.

Ferner ist in Betracht zu ziehen:

Wie aus dem vorhergehenden hervorgeht, kommen bei I paris verhältnissmässig viele spontan verlaufende Geburten vor, bei den späteren Entbindungen von Geburt zu Geburt immer weniger.

Hieraus lässt sich der weitere Schluss ableiten, dass die Mortalitätsziffern der Poliklinik desto weniger von den allgemeingültigen abweichen. je mehr Geburten vorangegangen sind. Für die I parae ist, mit anderen Worten, das Resultat der Poliklinik erheblich zu ungünstig, für die IV:XIII parae dagegen dürfte es dem allgemein gültigen ziemlich nahe kommen. 


\section{Abschnitt III.}

Die mit vorangehendem Kopfe verlaufenen Geburten, je nach verschiedenen Formen und Graden des engen Beckens.

Unter unseren 297 Geburten, die bei engem Becken mit vorangehendem Kopfe verlaufen sind, kamen vor:

1. Bei plattem Becken 209 Geburten, und zwar bei plattem Becken mit einer

Conjugata vera zwischen $93 / 4$ und $9 \mathrm{~cm}: 122$

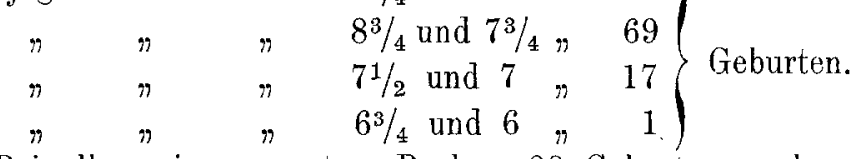

2. Bei allgemein verengtem Becken 88 Geburten und zwar bei allgemein verengtem Becken mit einer

Conjugata vera zwischen $9^{2} / 4$ und $9 \mathrm{~cm}: 30 j$

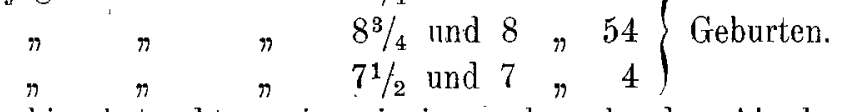

Auch hier betrachten wir, wie im vorhergehenden Abschnitte, die Geburten zunächst danach, in welcher Anzahl sie spontan, durch die gewöhnliche Zange, durch die hohe Zange oder durch die Kraniotomie beendet wurden: ${ }^{1}$ )

Auch bei der Betrachtung der folgenden Tabellen ist natürlich die Thatsache im Auge zu behalten, dass die spontan verlaufenden Entbindungen in der Poliklinik in verhältnissmässig geringer Anzahl zur Beobachtung gelangen.

Tabelle I. 1) Platte Becken.

\begin{tabular}{|c|c|c|c|c|c|c|c|c|}
\hline Unter: & $\begin{array}{r}\text { Spon } \\
\text { Gebu } \\
\text { Anzahl }\end{array}$ & $\begin{array}{l}\text { tane } \\
\text { rten } \\
\text { pCt. }\end{array}$ & $\begin{array}{r}\text { Gewöh } \\
\text { Zan } \\
\text { Anzahl }\end{array}$ & $\begin{array}{l}\text { nliche } \\
\text { gen } \\
\text { pCt. }\end{array}$ & $\begin{array}{r}\text { Ho } \\
\text { Zan } \\
\text { Anzahl }\end{array}$ & $\begin{array}{l}\text { he } \\
\text { gen } \\
\text { pCt. }\end{array}$ & $\begin{array}{l}\text { Kranic } \\
\text { Anzahl }\end{array}$ & $\begin{array}{l}\text { tomien } \\
\text { pCt. }\end{array}$ \\
\hline $\begin{array}{l}122 \text { Geburten mit } \\
\text { Conjug. vera von } \\
9^{3 / 4}-9 \mathrm{~cm} \text {. } \\
69 \text {. Geburten mit } \\
\text { Conjug. vera von } \\
8^{3 / 4}-7^{3} \cdot 4 \mathrm{~cm} \\
17 \text { Geburten mit } \\
\text { Conjug. vera von } \\
7^{1 / 2}-7 \mathrm{~cm} \text {. } \\
1 \text { Geburt mit Con- } \\
\text { jugata vera von } \\
6^{1 / 2}-6 \mathrm{~cm} \text {. }\end{array}$ & 23 & $\begin{array}{r}35,3 \\
0,0\end{array}$ & 44 & $\begin{array}{l}0,0 \\
0,0\end{array}$ & 18 & $\begin{array}{r}26,1 \\
11,8 \\
0,0\end{array}$ & $\begin{array}{l}11 \\
15\end{array}$ & $\begin{array}{r}9,0 \\
21,7 \\
52,9 \\
100\end{array}$ \\
\hline
\end{tabular}

1) Hinsichtjich der vergeblichen Zangenversuche gilt dio Anmerkung auf S. 287. 
294 Wolff, Weiterer Beitrag zur Therapie der Geburt beim engen Becken.

2) Allgomein verengte Becken.

\begin{tabular}{|c|c|c|c|c|c|c|c|c|}
\hline Unter: & \multicolumn{2}{|c|}{$\begin{array}{l}\text { Spontan ver- } \\
\text { laufene Geb. }\end{array}$} & \multicolumn{2}{|c|}{$\begin{array}{c}\text { Gewöhnliche } \\
\text { Zangen }\end{array}$} & \multicolumn{2}{|c|}{$\begin{array}{c}\text { Hohe } \\
\text { Zangen }\end{array}$} & \multicolumn{2}{|c|}{ Kraniotomien } \\
\hline $\begin{array}{l}30 \text { Fällen mit einer } \\
\text { Conjug. vera von } \\
9^{3 / 4}-9 \mathrm{~cm} \text {. } \\
54 \text { Fällen mit einer } \\
\text { Conjug. vera von } \\
8^{3 / 4-7} \text {. } \\
4 \text { Fällen mit einer } \\
\text { Conjug. vera von } \\
7^{1 / 2}-7 \mathrm{~cm} \text {. }\end{array}$ & 14 & 25,9 & $\begin{array}{c}16 \\
16 \\
1 \text { künst] } \\
\text { geb }\end{array}$ & $\begin{array}{l}29,6 \\
\text { I. Früh- } \\
\text { ourt }\end{array}$ & 14 & 25,9 & 10 & 75,0 \\
\hline
\end{tabular}

Was zunächst die Frequenz der spontan verlaufenen Entbindungen anbetrifft, so sei an Stelle einer Besprechung unserer aus den oben angeführten Gründen nicht allgemein gültigen Zahlen bemerkt, dass nach Weidling's (l. c.) sorgfältigen Untersuchungen unter der Gesammtzahl aller Entbindungen bei engem Becken die Anzahl der spontan verlaufenden mit zunehmender Beckenenge in sehr rascher Progression sinkt. -

lnteressante Verhältnisse ergiebt unsere Tabelle für die Zangenoperationen und für die Kraniotomien:

Die Zangenoperationen bei tief stehendem Kopfe nehmen mit dem höheren Grade der Beckenverengung an Häufigkeit bedeutend ab.

Die hohen Zangen dagegen erreichen ihre Maximalzahl sowohl unter den platten wie unter den allgemein verengten Becken bei einer Conjugata vera zwischen $8^{3} / 4$ und $7^{3} / 4 \mathrm{~cm}$. - Bei den höheren Graden der Beckenverengung sind sie, ebenso wie bei den geringeren Graden seltener. -

Die Frequenz der Kraniotomien ist desto grösser, je stärker das Becken verengt ist. -

Um ein anschaulicheres Bild von den mehr oder weniger grossen Schwierigkeiten des Geburtsverlaufes je nach den verschiedenen Formen und Graden der Beckenverengung zu geben, fassen wir in der folgenden Tabelle, ebenso wie in der Tabelle II des vorigen Abschnittes gesehehen ist, hohe Zangen und Kraniotomien als die "schwieriger verlaufenen" Entbindungen zusammen: 


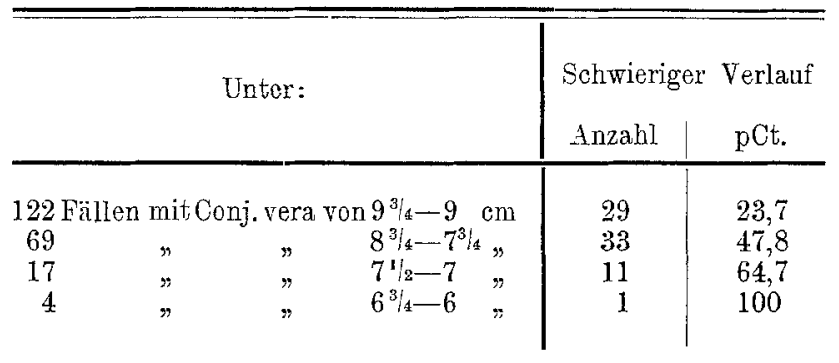

2) Allgemein verengte Becken:

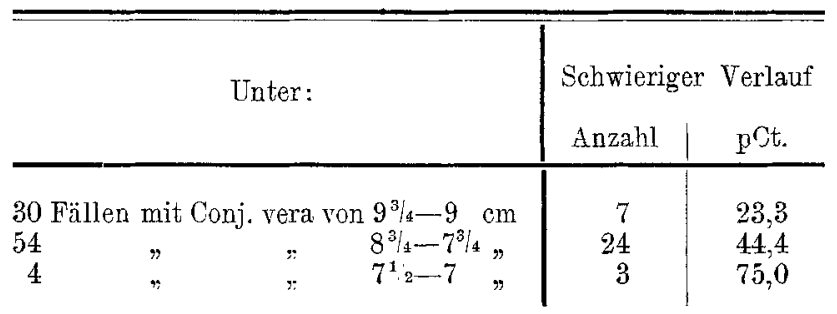

Es ergiebt sich aus dieser Zusammenstellung sehr deutlich, in wie hohem Maasse mit zunehmender Beckenenge die Schwierigkeiten der mit vorangehendem Kopfe verlaufenden Geburten zunehmen.

Dagegen liessen sich in dieser Hinsicht zwischen den platten und allgemein verengten Becken für gleiche Grade der Verengung keine wesentlichen Unterschiede entnehmen. -

Wir haben nun noch die Mortalitätsziffern bei den verschiedenen Formen und Graden des engen Beckens zu ermitteln:

Was die Mütter anbetrifit, sei nur kurz erwähnt, dass der Exitus letalis eintrat:

Bei plattem Becken mit einer Conj. vera von $91 / 2$ bezw.

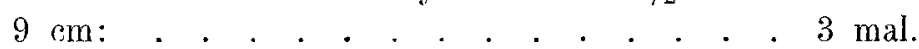

Bei allgemein verengtem Becken mit einer Conj. vera von

8 bezw. $7 \frac{1}{2}-8 \mathrm{~cm}:$. . . . . . . . . $3 \mathrm{mal}$.

Die folgende Tabelle giebt eine Uebersicht über die Mortalität der Kinder ${ }^{1}$ ).

1) Die 18 durch Nabelschnurvorfall gestorbenen Kinder und das eine schon vor Anlegung der Zange todte Kind sind wiederum nicht mit berücksichtigt. 
296 Wolft, Weiterer Beitrag zur' 'l'herapie der Geburt beim engen Becken.

Tabello III.

1) Platte Becken:

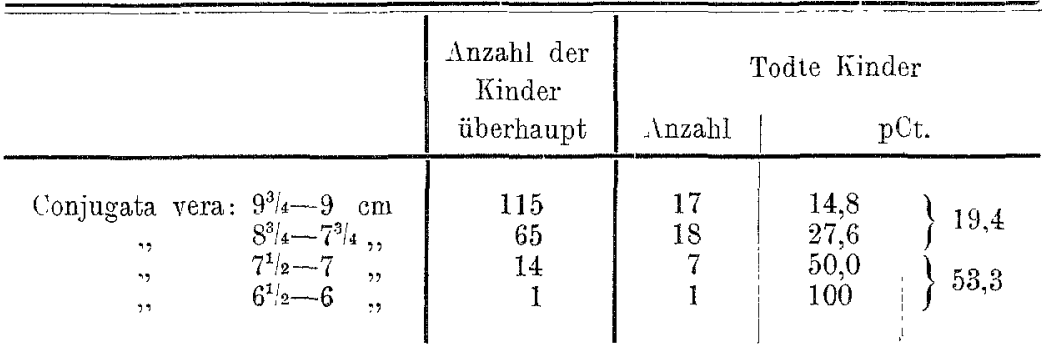

2) Allgemein verengte Becken:

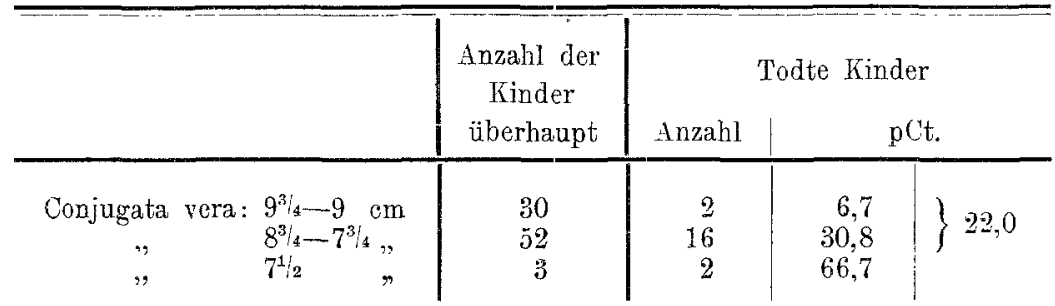

Aus dieser Statistik geht hervor, wie erheblich mit zunehmender Beckenenge, entsprechend den grösseren Schwierigkeiten des Geburtsverlaufes, auch die Mortalität der Kinder, die mit vorangehendem Kopfe geboren werden, zunimmt.

Fasst man die Geburten bei Recken mit einer Conjugata vera von $93 / 4-73 / 4 \mathrm{~cm}$ zusammen, so zeigt es sich, dass unter diesen der Procentsatz der todten Kinder beim allgemein verengten Becken nicht unbedeutend höher als beim platten Becken gewesen ist. -

Sondern wir die allgemein verengten und die platten Becken nicht von einander, so findet man im Ganzen:

Bei einer Conj. vera zwischen $93 / 4$ und $73 / 4 \mathrm{~cm}: 20,2 \%$ todte Kinder.

Bei einer Conj. vera zwischen $7 \frac{1}{2}$ und $6 \mathrm{~cm}: 55,6 \%$ todte Kinder. -

Sucht man aus diesen für die Poliklinik gefundenen Mortalitätszahlen einen Rückschluss auf die Verhältnisse im Allgemeinen ${ }^{1}$ zu gewinnen, so ist wiederum die Thatsache in Rechnung zu ziehen, dass wir in der Poliklinik besonders wenig spontan verlaufende Entbindungen zu beobachten Gelegenheit hatten.

1) Siehe oben Seite 292 . 
Bei einer Conj. vera $z$ wischen $93 / 4$ und $7^{3 / 4} \mathrm{~cm}$ verlaufen nun, wie oben erörtert, im Ganzen viele Entbindungen spontan.

Bei einer Conj. vera von $7 \frac{1}{2}-6 \mathrm{~cm}$ dagegen gehen nur noch verhältnissmässig wenige Geburten spontan zu Ende. Ein so hoher Grad der Beckenverengung wird gewöhnlich auch von den Hebammen sofort erkannt, und, während die Hebammen bei geringen Graden der Beckenverengung gewöhnlich erst auf besondere Störungen im Geburtsverlauf hin den Arzt zuziehen, rufen sie bei den stark verengten Becken meistens den Arzt schon der Beckenverengung als solcher wegen.

Man muss daher in der Poliklinik von den bei stark verengten Becken überhaupt vorkommenden Geburten ein viel vollständigeres Bild als von denen bei mässig verengten Becken bekommen. -

Da nun die Mortalität bei den spontan verlaufenden Geburten eine verhältnissmässig geringe ist, so ist folgender Schluss hiernach berechtigt:

Für die mässig verengten Becken (Conj. vera von $93 / 4-7^{3} / 4 \mathrm{~cm}$ ) muss die von uns gefundene Mortalitätsziffer $(20,2 \%$ ) erheblich zu ungünstig der allgemein gültigen ${ }^{1}$ ) gegenüber sein. -

Für die stark verengten Becken (Conj. vera von $71 / 2-6 \mathrm{~cm}$ ) dagegen dürfte die von uns gefundene Mortalitätsziffer $(55,6 \%)$, wenn auch nicht vollständig, so doch annähernd mit der allgemein gültigen ${ }^{1}$ ) übereinstimmen. -

Auf noch einen Punkt ist hierbei hinzuweisen:

Die Differenz in der Prognose für die Kinder zwischen den Becken mit einer Conj. vera von $93 / 4-73 / 4 \mathrm{~cm}$ und den Becken mit einer Conj. vera zwischen $71 / 2$ und $6 \mathrm{~cm}$ war in der Poliklinik eine ausserordentlich grosse; der Unterschied in der Mortalität betrug. $35,4 \%$.-

Da wir nun soeben zu dem Resultat gelangt sind, dass die Yortalitätsziffer von $20,2 \%$ der allgemein gültigen gegenüber erheblich zu hoch ist, die Mortalitätsziffer von 55,6\% dagegen mit der allgemein gültigen annähernd übereinstimmt, so ist ohne weiteres $z u$ schliessen:

Die Differenz, die sich hinsichtlich der Mortalität der mit vorangehendem Kopfe geborenen Kinder zwischen den Becken mit Conj. vera von $93 / 4-73 / 4 \mathrm{~cm}$ und den Becken mit einer Conj. vera

1) Siehe oben Seite 292. 
298 Wolff, Weiterer Beitrag zur Therapie der Geburt beim engen Becken.

von $71 / 2-6 \mathrm{~cm}$ ergeben würde, wenn die Möglichkeit geboten wäre, alle in einem bestimmten Distrikt vorkommenden Entbindungen ärztlich zu beobachten, würde noch grösser scin, als die ist, die sich unter den poliklinischen Verhältnissen thatsächlich ergeben hat. -

\section{Schlussbemerkungen.}

Nachdem ich somit über die bei engem Becken ausgeführten Wendungen in meiner früheren(1.c.), über die mit vorangehendem Kopfe verlaufenen Geburten in der hier vorliegenden Arbeit berichtet habe, sei es gestattet auf das gesammte besprochene Material noch einen Rückblick zu werfen. Bei dieser Gelegenheit will ich vor allen Dingen auch die Resultate mit einander in Vergleich stellen, die einerseits durch die Wendung und Extraction, speciell durch die prophylaktische Wendung, andererseits durch das abwartende Verfahren bei engem Becken erzielt worden sind.

Die in der Abhandlung über die Wendung und Extraction mitgetheilten Ergebnisse bezogen sich, wie erwähnt, auf das Material der Jahre 1892-1900. Im Folgenden werde ich an Stelle der dort mitgetheilten Zahlen stets diejenigen setzen, die festzustellen waren, nachdem jeh auch für die Wendungen, ebenso wie für die mit vorangehendem Kopfe verlaufenen Geburten, die Jahrgänge 1900-1902 mitberücksichtigt habe. -

Was zunächst die Mütter anbetrifft, so war die Mortalität dieser die folgende:

Unter 243 Fällen von Wendung bezw. Wendung und Extraction starben 5 Mütter (= 2,1 \%).

Von diesen Todesfällen waren verursacht:

durch Eklampsie: 1,

durch die Narkose: 1 ,

durch Uterusruptur: 2,

durch Sepsis: 1.

Unte. den 297 Fällen, in denen die Geburt mit vorangehendem Kopfe verlief, starben 6 Mütter $(=2,0 \%)$.

Von diesen Todesfällen waren verursacht:

durch Uterusruptur: 2,

durch Sepsis: 3 ,

durch Lungenembolie (?): $1 . \ldots 1$ )

1) Todesursache nicht mit Sicherheit ermittelt. 
Wolff, Weiterer Beitrag zur Therapie der Geburt beim engen Becken.

Für die Kinder war die Gesammtmortalität: $\left.{ }^{1}\right)$

Unter 243 Fällen von Wendung (bezw. Wendung und Extraction): 57 todte Kinder $(=23,4 \%$ ).

Unter 297 Geburten $\left.{ }^{2}\right)$ in Kopflage: 81 todte Kinder $(=27,2 \%$ ).

Die für die Kinder erzielten Resultate wollen wir in den folgenden Tabellen, unter besonderem Hinblick auf die Frage der prophylaktischen Wendung, noch specieller gruppiren. (Siehe Tabellen auf Seite 300.) -

Diese Tabellen beweisen zunächst, wie ausserordentlich gross der Unterschied in der Prognose der Geburten bei Becken mit einer Conjugata vera von $93 / 4-73 / 4 \mathrm{~cm}$ und der Geburten bei Becken mit einer Conj. vera von $71 / 2-6 \mathrm{~cm}$ in jeder Hinsicht ist. Bei der Erörterung der Therapie des engen Beckens muss daher auf diese Differenz in erster Linie Rücksicht genommen werden. -

Künstliche Frühgeburt, Symphyseotomie und Kaiserschnitt sind im allgemeinen erst bei einer Conjugata vera unter $73 / 4 \mathrm{~cm}$ in Betracht zu ziehen; denn bis zu diesem Grade der Beckenverengung herab sind, wenigstens bei Mehrgebärenden, fast absolut gute Resultate für die Kinder zu erzielen, wenn es gelingt, die Blase bis zur vollständigen Eröffnung des Muttermundes zu erhalten ${ }^{3}$ ) und wenn man dann unter diesen günstigen Bedingungen, die Wendung und Extraction vornimmt.

Unsere Tabelle A zeigt nämlich, dass unter nunmehr") 69 Wendungen, die bei stehender Blase (bezw. unmittelbar nach dem Blasensprung), vollständig erweitertem Muttermund und einer Conjugata vera von $9^{3} / 4-7^{3 / 4} \mathrm{~cm}$ ausgeführt worden sind, nur ein Kind todt zur Welt kam; 68 Kinder $=98,6$ pCt. wurden lebend geboren. -

1) Die in den ersten Lebenstagen an den Folgen der Geburt gestorbenen Kinder sind stets mit zu den todten gerechnet.

2) 298 Kinder (1 mal Zwillinge).

3) Alle der Erhaltung der Fruchtblase dienenden Maassnahmen, insbesondere die Colpearyse, wie sie besonders in den Arbeiten der Schüler Leopold's empfohlen worden ist, sind daher von allergrösster Wichtigkeit. - Vgl. Rosenthal, Enges Becken und Colpeurynter. Dieses Archiv. Bd.45. 1895. - Voigt, Die vaginale Anwendang der Braun'schen Blase in der Geburtshülfe. Dieses Archiv. Bd. 66. 1902.

4) In der Arbeit über die Wendungen berichtete ich, dass unter 58 Fällen dieser Art ein Kind todt geboren wurde und $57(=98,3$ pCt.) lebend zur'Welt kamen. 
A. Becken mit einer Conj. vera von $\left.9^{3 / 4}-7^{3 / 4} \mathrm{~cm}^{1}\right)$.

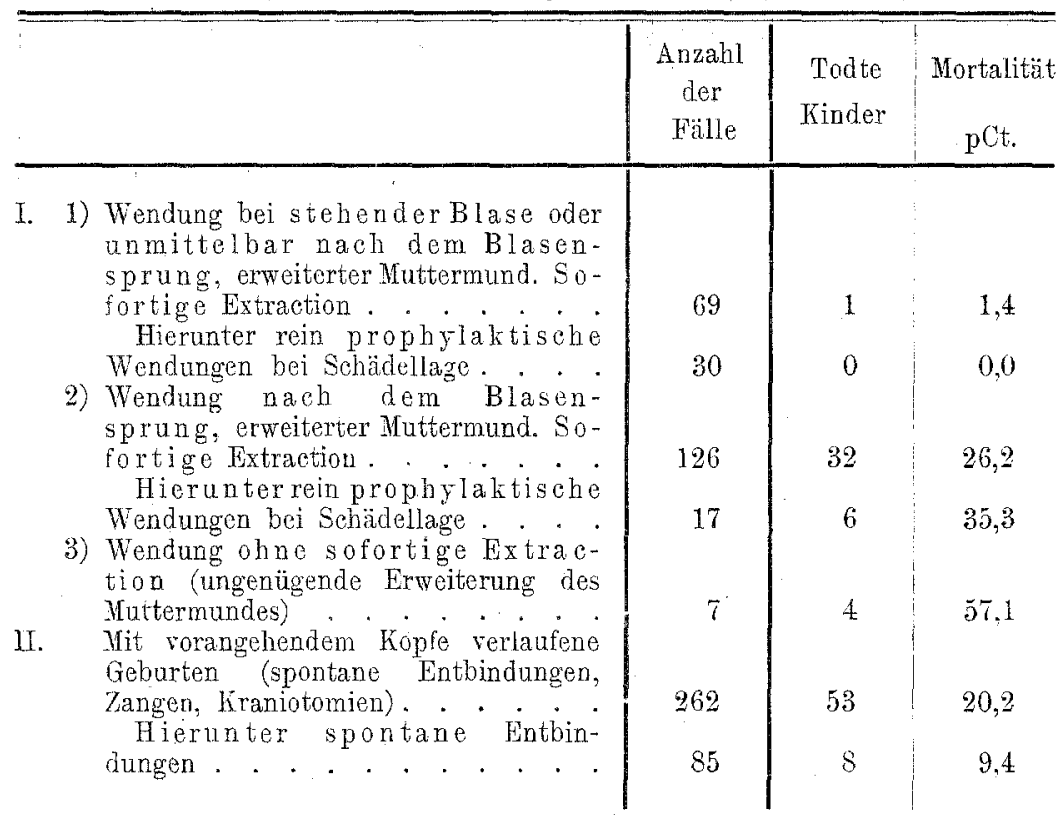

B. Beeken mit einer Conj. vera von $\left.7^{1 / 2}-6 \mathrm{~cm}^{1}\right)$.

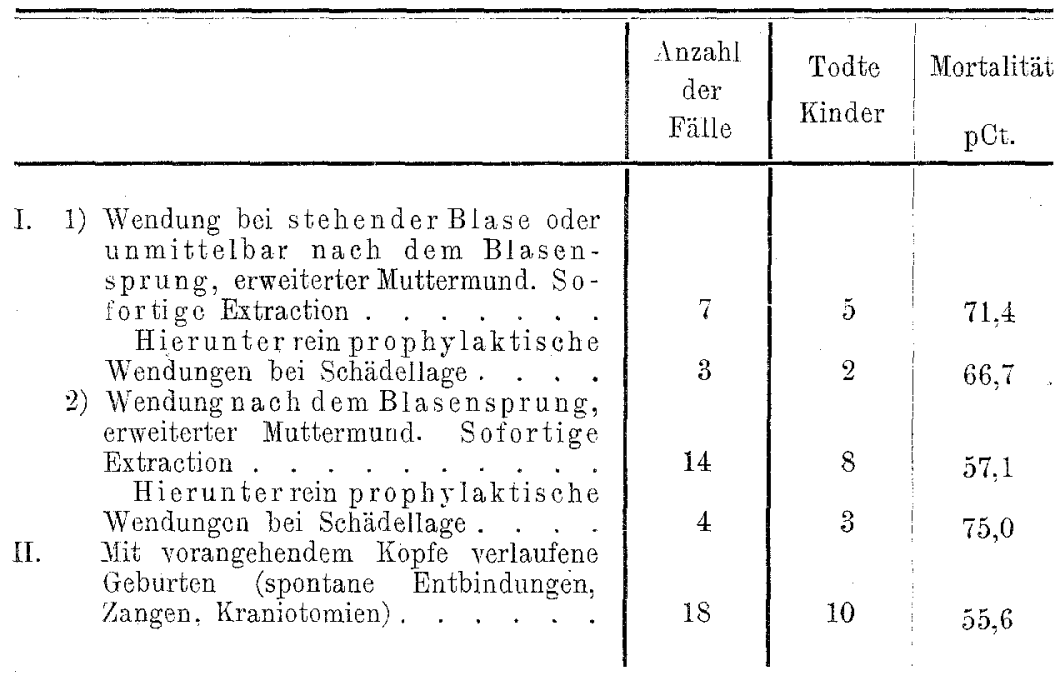

1) Bei den Zahlen der folgenden Tabelle sind von den Wondungen diejenigen Fälle nicht mitberürksichtigt, in denen das Kind mit Sicherheit bereits vor der Wendung todt oder die Geburt durch Eklampsie, Placenta praeria oder vorzeitige Placentarlösung complicirt war 
Da zu den mittelst des abwartenden Verfahrens (im Gegensatz zur prophylaktischen Wendung) behandelten Geburten alle diejenigen gehören, die in Kopflage verliefen, sei es nun, dass sie spontan oder durch die Zange oder die Kraniotomie (oder die Symphyseotomie) beendet wurden, so ergiebt ein Vergleich zwischen den Resultaten des abwartenden Verfahrens und den Resultaten der prophylaktischen Wendung für den augenblicklich in Rede stehenden Grad der Beckenverengung folgendes:

Prophylaktische Wendung und Extraction bei stehender Blase (bezw. unmittelbar nach dem

Blasensprung): . . . . . 30 Fälle, -0 pCt. Mortalität. Abwartendes Verfahren: . . . $262 " 20,2$, "

Prophylaktische Wendung nach

dem Blasensprung. - Extraction: . . . . . . $17 n-35,3 n$ "

Nun ist allerdings, wie im vorhergehenden ${ }^{1}$ ) besprochen wurde, die Mortalitätsziffer 20,2 pCt. für das abwartende Verfahren eine aus dem*Grunde sehr hohe, weil in der Poliklinik vorwiegend operative Geburten beobachtet wurden: Der Vergleich dieser Zahl mit der Mortalitätsziffer "0 pCt." der bei stehender Blase ausgeführten prophylaktischen Wendungen wäre daher nicht ohne weiteres berechtigt.

Wie günstig das Resultat der Gruppe von prophylaktischen Wendungen, die bei stehender Blase und einer Conj. vera zwischen $93 / 4$ and $73 / 4 \mathrm{~cm}$ vorgenommen wurden, ist, lässt sich trotzdem aber an unserem Material zeigen; denn es ergiebt sich dies sogar schon aus folgendem:

Wir führen die prophylaktische Wendung gerade deshalb aus, um der Möglichkeit vorzubeugen, dass bei abwartendem Verhalten eine hohe Zange, Kraniotomie oder Symphyseotomie nothwendig wird.

(siehe dieses Archiv, Bd. 62, S. 582, Anmerliung.) - Von den mit vorangehendem Kopfe verlaufenen Geburten sind die nicht berücksichtigt, in denen die Kinder durch. Vorfall der Nabelschnur starben und diejenige, in der das Kind bereits vor Anlegung der Zange to dt war.

1) Siehe oben S. $29 \%$. 
302 Wolff, Weiterer Beitrag zur Therapie der Geburt beim engen Beclien.

Wenn wir nun aber zum Vergleich mit der prophylaktischen Wendung sogar lediglich die spontan in Kopflage beendeten Geburten heranziehen, so fällt selbst beim Vergleich mit dieser einzelnen ganz besonders günstig verlaufenen Gruppe der abwartend behandelten Geburten das Resultat sehr erheblich zu Gunsten der bei stehender Blase ausgeführten prophylaktischen Wendungen aus; denn es hatten die in Kopflage spontan beendeten Entbindungen bei den Becken mit einer Conjugata vera von $9^{3 / 4}$ bis $7^{3 / 4} \mathrm{~cm}$ immer noch eine Mortalität von $9,4 \mathrm{pCt}$. -

Auf der anderen Seite aber sehen wir allerdings, dass die prophylaktische Wendung, wenn sie erst nach dem Blasensprung vorgenommen wird, bei ebendiesen Graden der Beckenverengung, ein viel ungünstigeres Resultat ergiebt, als es das abwartende Verfahren selbst nach der poliklinischen Statistik hatte. -

Hieraus folgt für die Indicationsstellung der prophylaktischen Wendung, dass bei den engen Becken mit einer Conj. vera bis zu $73 / 4 \mathrm{~cm}$ herunter im Allgemeinen von der prophylaktischen Wendung dann Abstand zu nehmen ist, wenn dieselbe nicht mehr bei stehender Blase, sondern erst nach dem Blasen,sprung ausgeführt werden könnte. ${ }^{1}$ ) -

Ich weise darauf hin, dass ich ausfübrlich die Gründe erörtert babe ${ }^{2}$ ) aus denen gerade bei den Becken mit einer Conj. vera von $9^{3 / 4}-73 / 4 \mathrm{~cm}$ es von so ausserordentlich hoher Bedeatung für das Frgebniss der Wendung and Extraction ist, ob die Blase zur Zeit der Wendung stand oder schon gesprungen war.

Was nun die Indicationen der prophylaktischen Wendungen bei stehender Blase, vollständig erweitertem Muttermund und Beckenverengung I. Grades anbetrifft, so muss man hier bei jeder einzelnen Entbindung die besonderen Umstände berücksichtigen:

1) Es kann natürlich, - - [meiner Erfahrung nach kommt es jedoch nur sehrselten vor] - eine [ndication eintreten, die Wendung bei Schädellage noch nach dem Blasensprung auszuführen, wenn nämlich andavernde absolute Wehenschwäche besteht oder Störungen im Befinden der Mutter oder des Kindes sich einstellen. Von einer prophylaktischen Wendung aber lian man dann vicht mehr sprechen, vielmehr handelt es sich dann um eine indicirte Wendung. - Fast immer steht der Kopf, wenn sich Störungen im Befinden der Mutter oder des Kindes zeigen, schon so fest im Becken oder im urteren Uterinsegment, dass man dringend rathen muss, die für Mutter and Kind in gleichem Maasse gefährliche Wendung dann zu unterlassen.

2) Dieses Arehiv. Bd. 62. S. $584 \mathrm{ss.}$ 
Wolff, Weiterer Beitrag zur Therapie der Geburt beim engen Becken. 303

Bei Erstgebärenden ist von der prophylaktischen Wendung and Extraction auch bei stehender Blase im Allgemeinen abzuratben, da, wie oben besprochen, bei Primiparis die Geburt mit rorangehendem Kopfe besonders günstig zu verlaufen pflegt. Andererseits ist zweifellos bei Erstgebärenden die Wendung und Extraction gefährlicher und schwieriger als bei Mehrgebärenden [Winter (l.c.)].

Bei Mehrgebärenden findet man häufig bej vollständig erweitertem Muttermund und stehender Blase einen bereits so günstigen Stand des Kopfes, dass man ohne weiteres einen günstigen Ausgang der Geburt in Schädellage voraussehen kann, besonders wenn frühere Geburten mit vorangehendem Kopfe ein gutes Resultat aufzuweisen hatten und die Wehenthätigkeit eine befriedigende ist. Auch unter diesen Umständen wird man natürlich nicht prophylaktisch wenden. -

Es bleibt aber eine nicht geringe Anzahl von Entbindungen Mehrgebärender übrig, in denen dem Untersuchungsbefund bej stehender Blase und vollständig erweitertem Muttermund und der Anamnese nach der gute Verlauf der Geburt in Schädellage zwar nicht ausgeschlossen, aber doch mehr oder weniger $z$ weifelh aft erscheinen muss. In allen in dieser Richtung $z$ weifelhaften Beobachtungen soll man, - im Hinblick auf die Sicherheit des Erfolges, den die Wendung und Extraction unter diesen Umständen gewährt, ohne erst noch abzuwarten, bei stehender Blase die propbylaktische Wendung vornehmen. - Bei dieser Art der Indicationsstellung ist besonders im Auge zu behalten, dass desto grössere Schwierigkeiten für den Verlauf der Geburt in Schädellage vorherzusehen sind, je mehr Entbindungen die Kreissende schon überstanden bat. -

Wir kommen nun noch zu den Becken mit einer Conj. vera $z$ wischen $71 / 2$ und $6 \mathrm{~cm}$ :

Ein Vergleich zwischen den Ergebnissen der prophylaktischen Wendung und den Ergebnissen des abwartenden Verfahrens erlaubt, da die Resultate nicht sehr erheblich von einander verschieden waren, und da die Anzahl dieser Entbindungen in der Poliklinik eine ziemlich geringe war, keine endgültige Entscheidung, in wie weit hier die prophylaktisehe Wendung für das Kind von Vortheil oder Nachtheil gewesen ist.

Ich muss aber erwähnen, dass einzelne poliklinische Erfahrungen jedenfalls dafür sprechen, dass auch bei diesem Grade 
304 W.olf, Weiterer Beitrag zur Therapie der Geburt beim engen Becken.

der Beckenverengung die prophylaktische Wendung zuweilen dem Kinde bessere Aussichten als das abwartende Verfahren giebt:

In der Poliklinik wurde folgender Fall beobachtet: Fall Kornetzky. Rachitisch plattes Becken. Spinae 28, Cristae 281/2, Trochant. 31. Conj. ext. 16//2, Conj. diagon. $91 / 2 \mathrm{~cm}$ (Conj. vera, berechnet auf $71 / 2 \mathrm{~cm})$. - Die Patientin ist in den Jahren 1886-1901 im Ganzen $z w o ̈ l f m a l$ durch die Poliklinik entbunden worden. Aus den über diese 12 Entbindungen vorhandenen Aufzeichnungen geht hervor, dass 4 Geburten in Ko pflage zu Ende gingen; in diesen 4 Fällen musste stets die Kraniotomie ausgeführt werden ( 1 mal bei lebendem Kinde und $3 \mathrm{mal}$, nachdem das Kind in Folge von Nabelschnurvorfall abgestorben war). - $7 \mathrm{mal}$ wurde die Wendung und Extraction vorgenommen und einmal wurde bei Steisslage der vordere Fuss heruntergeholt und extrahirt. Unter diesen letzteren 8 Entbindungen kam das Kind 4 mal todt und 4 mal lebend zur Welt; von den 4 lebend geborenen Kindern starb allerdings eins kurze Zeit nach der Geburt an den Folgen einer Verletzung im Munde, die es bei der Kopfentwickelung erlitten hatte. -

Bei dieser Frau war also der Verlauf der Geburten in Kopflage ein absolut schlechter, während bei den Geburten, wo der Kopf nachfolgte und die Extraction vorgenommen wurde, wenigstens einige Kinder gerettet werden konnten. -

Am Schlusse dieser Arbeit betone ich folgendes:

Im Gegensatz zu den Autoren, die in neuerer Zeit theils die prophylaktische Wendung und die hohe Zange, theils die Kraniotomie vollständig bei engem Becken verwerfen, meine ich, dass diese drei Operationen keineswegs aus der Therapie der Geburt bei engem Becken verbannt werden dürfen.

Prophylaktische Wendung und hohe Zange sind vielmehr vielfach dazu geeignet, das in Folge der Beckenverengung gefährdete kindliche Leben zu erhalten und die Kraniotomie ist in der Praxis für viele Fälle leider noch als unentbehrlich anzusehen. -

Die prophylaktische Wendung und die hohe Zange haben in ihrer Leistungsfähigkeit natürlich ihre Grenzen.

Es ist daher von grösstem Werthe, durch die Vervollkommnung der Technik der Symphyseotomie und des Kaiserscbnittes die Indicationen für diese letzteren Operationen im lnteresse der Kinder allmählich immer weiter ausdehnen zu kömnen und dadurch eine grössere Anzahl von Kindern, als früher möglich war, am Jeben zu erhalten. -

Alle Fortschritte aber, die in der Technik der Symphyseotomie und des Kaiserschnittes schon gemacht sind, haben bisher die prophylaktische Wendung, die hohe Zange und die Kraniotomie beim engen Becken in keiner Weise entbehrlich gemacht. - 